\title{
Alimentação: um direito humano em disputa - focos temáticos para compreensão e atuação em segurança alimentar e nutricional
}

\author{
Food: a disputed human right - a thematic focus \\ for comprehension and action in food and nutritional security
}

Lúcia Dias da Silva Guerra (https://orcid.org/0000-0003-0093-2687) ${ }^{1}$

Ana Maria Cervato-Mancuso (https://orcid.org/0000-0002-9276-8943) ${ }^{1}$

Aída Couto Dinucci Bezerra (https://orcid.org/0000-0001-9132-4390) ${ }^{2}$

${ }^{1}$ Faculdade de Saúde Pública, Universidade de São Paulo. Av. Dr. Arnaldo 715, Cerqueira Cesar. 01246904 São Paulo SP Brasil. ludsguerra@gmail.com ${ }^{2}$ Faculdade de Nutrição, Universidade Federal de Mato Grosso. Cuiabá MT Brasil.

\begin{abstract}
Situations involving food and nutritional insecurity are impediments to the realization of the human right to adequate food and may be linked to the availability, access, consumption, production and biological use of food and social, political and economic issues, which illustrate the current food problems existing between countries. The aim is to review how food is perceived as a human right in the scientific production on health in articles dedicated to the empirical analysis of food and nutritional security among children and adolescents in different urban settings. An integrated review of the literature was conducted with 80 scientific articles published in the PubMed database from 2007 to 2016. Information about the methodological approaches, the aspects related to food and nutritional insecurity, as well as conclusions and recommendations were extracted from the studies. The review revealed the diversity of the thematic focus for understanding food as a human right and its relation to other rights. Suggested action strategies focused on primary health care. Food in both developed and developing countries is a disputed human right that needs to be addressed in order to achieve social justice for all mankind.

Key words Food and nutrition security, Human rights, Public health, Public policies
\end{abstract}

Resumo As situações de insegurança alimentar e nutricional (IAN) são impeditivos para a concretização do direito humano à alimentação adequada (DHAA) e podem estar ligadas à disponibilidade, ao acesso, ao consumo, à produção, à utilização biológica dos alimentos e às questões sociais, politicas e econômicas, que expressam os problemas alimentares atuais existentes entre os países. O objetivo é revisar como a alimentação é compreendida enquanto um direito humano na produção científica da área da saúde, em artigos que se dedicaram à análise empírica da SAN em diferentes cenários urbanos com crianças e adolescentes. Realizou-se uma revisão integrativa da literatura, com 80 artigos científicos disponiveis na base de dados PubMed, publicados no periodo de 2007 a 2016. Foram extraídas dos estudos informações a respeito dos cenários de investigação, abordagens metodológicas, aspectos relacionados à IAN, conclusões e recomendações. Esta revisão mostrou a diversidade dos focos temáticos para a compreensão da alimentação como um direito humano e as estratégias de ação tiveram como foco os cuidados primários em saúde. A alimentação, tanto nos países desenvolvidos quanto nos que estão em desenvolvimento, é um direito humano em disputa que necessita efetivação, visando à justiça social para todas as pessoas.

Palavras-chave Segurança alimentar e nutricional, Direitos humanos, Saúde pública, Políticas públicas 


\section{Introdução}

A alimentação e a nutrição são questões globais e locais relevantes para a saúde pública ${ }^{1,2}$, que no cenário contemporâneo têm mobilizado organizações (internacionais e nacionais) e países para a criação e implementação de políticas públicas que visam à garantia e a efetivação do Direito Humano à Alimentação Adequada (DHAA). Essas políticas públicas trazem como foco ações em Segurança Alimentar e Nutricional (SAN) nas suas diversas dimensões: disponibilidade, acesso, consumo, produção e utilização biológica dos alimentos ${ }^{3}$.

É direito de todo ser humano ter uma alimentação adequada e saudável, do ponto de vista da saúde, do respeito à cultura alimentar, da sustentabilidade econômica, social, ambiental, da disponibilidade e do acesso permanente aos alimentos de qualidade, sem comprometer outras necessidades inerentes a uma vida digna, como a educação, moradia, emprego e lazer 4 .

Contudo, os problemas alimentares contemporâneos permanecem atravessados pela transformação de bens essenciais aos seres humanos em mercadoria, como é o caso dos alimentos. Nesse contexto, observa-se que os alimentos são distribuídos de acordo com as leis da oferta e da demanda - um traço importante do capitalismo contemporâneo e uma das chaves para explicar o atual cenário produtor de doenças e de desigualdades econômicas e sociais, que impacta sobre os sistemas alimentares globais e impõe desafios no campo da saúde pública, criando obstáculos para a consolidação da SAN e a efetivação dos direitos humanos em diversos países ${ }^{2,5,6}$.

O Konzernatlas - Atlas das Multinacionais $(2017)^{7}$ mostra a influência do capitalismo na alimentação humana, com destaque para o agronegócio, a indústria de alimentos e a rede de distribuição/comercialização que representam ameaças à soberania alimentar dos países e a luta por sistemas alimentares sustentáveis. O Konzernatlas destaca questões, como a concentração na produção de sementes e o comércio dos agrotóxicos que definem o que e como se planta, consequentemente, a qualidade do que se come.

Em cenários urbanos, a expressão do capitalismo na alimentação humana pode ser observada por meio do crescimento de ambientes alimentares agressivos, principalmente, do ponto de vista mercadológico e publicitário. Além de alimentar e nutricionalmente pouco saudáveis, são repletos de alimentos altamente industrializados (ricos em açúcar, sal, gordura) e com diversos aditivos químicos. Tudo isso apresentado com fácil acesso e baixo custo e expressivo emprego de estratégias de comunicação e publicidade que visam atrair como público alvo crianças e adolescentes para o consumo destes alimentos ${ }^{8-10}$. Tal fato tem gerado impactos financeiros significativos para o setor saúde ${ }^{11}$. Assim, considerando que crianças e adolescentes são parte essencial para a garantia das futuras gerações e neste contexto está em disputa a ideia de justiça intergeracional, o mundo em desenvolvimento já aponta os impactos que a globalização e a urbanização têm gerado na alimentação para a vida humana ${ }^{12,13}$.

No âmbito internacional, a Organização das Nações Unidas - ONU tem empregado esforços para enfrentar questões ligadas a SAN e os direitos humanos, a exemplo do direito humano à alimentação adequada. No entanto, as metas firmadas entre os países membros da ONU, nos Objetivos de Desenvolvimento do Milênio (Meta 1 - "erradicar a fome e a miséria") e nos 17 Objetivos de Desenvolvimento Sustentável (Meta 2 - "fome zero e agricultura sustentável"), carecem de implementação no plano local, pois ainda permanecem no mundo 795 milhões de pessoas em situação de fome, que estão localizadas principalmente em regiões do oeste da Ásia, África Central, África Subsaariana e alguns países da América Latina ${ }^{14}$.

No caso do Brasil, nos últimos 10 anos foi possível observar a institucionalização normativa do DHAA, com a promulgação da Lei Orgânica de SAN - LOSAN no 11.346/2006 que lançou as bases para a criação de um ordenamento jurídico nacional, a disponibilização de mecanismos e instrumentos necessários a sua operacionalização por meio de políticas públicas, como a Política Nacional de SAN - PNSAN; e criou o Sistema Nacional de SAN (SISAN). A LOSAN como primeiro marco jurídico para o DHAA implicou na instituição formal desse direito, com posterior incorporação na Constituição Federal (1988) através da Emenda Constitucional no 64/2010. Deste modo, o DHAA está relacionado a outros direitos e a sua não garantia, proteção e efetivação podem gerar situações de Insegurança Alimentar e Nutricional (IAN) que se revelam como um processo progressivo, gerenciado tanto no âmbito coletivo quanto no individual e estão relacionadas à piora da saúde (anemia, desnutrição, hipovitaminoses, obesidade, diabetes, hipertensão, síndromes metabólicas, asma, cárie, HIV/Aids), ao aumento da violência doméstica e comunitária, dos transtornos mentais, ao fortalecimento da construção de uma estrutura de 
produção de alimentos predatória em relação ao ambiente, aos preços abusivos dos bens essenciais e à imposição de padrões alimentares que não respeitam a diversidade cultural ${ }^{15-17}$.

Diante disso, este artigo tem por objetivo revisar como a alimentação é compreendida enquanto um direito humano na produção científica da área da saúde, especificamente, em artigos que se dedicaram a análise empírica da SAN em diferentes cenários urbanos com crianças e adolescentes.

\section{Percurso metodológico}

Este estudo é uma revisão integrativa desenvolvida a partir da seleção sistemática da literatura científica, que possibilita um aprofundamento na compreensão de um determinado fenômeno com base em estudos anteriores, a construção de uma análise sobre as abordagens metodológicas e atualização dos resultados de pesquisas, além de reflexões sobre a realização de futuros estudos e a tomada de decisões com relação a intervenções ${ }^{18}$.

A busca bibliográfica dos artigos foi realizada na base de dados PubMed, do National Center for Biotechnology Information (NCBI), uma das bases mais utilizadas na área das ciências da saúde. Essa busca ocorreu em três etapas (Figura 1).

Na Etapa 1 de identificação e escolha do descritor a ser utilizado (Figura 1), foi consultado o Descritor Mesh (Medical Subject Headings) recurso da base de dados PubMed para a identificação da terminologia padronizada que auxilia na definição dos assuntos e na recuperação dos artigos de interesse. No entanto, o termo encontrado foi food supply, pouco utilizado nos títulos, resumos e palavras-chave, de artigos sobre IAN que têm como foco a abordagem da alimentação e nutrição no contexto da saúde pública. Assim, considerando o conhecimento dos autores sobre o tema, optou-se pelo uso do termo livre food insecurity mais presente nas publicações científicas de interesse do estudo. $O$ intuito foi obter uma busca mais abrangente que permitisse capturar as demais variações do termo.

Assim, realizou-se a busca livre na base de dados com o termo food insecurity, a busca exata food insecurity e a busca avançada com a expressão food AND insecurity. Em adicional, optou-se por realizar também a busca livre com os termos human rigth to adequate food, human rigths dimensions of food a busca exata com human rigths dimensions of food e human rigth to adequate food. Foram identificadas 12.950 publicações.
Após esse teste com os termos, selecionou-se alguns filtros da própria base de dados para aprimorar a busca, segundo o tipo de artigo (journal article), texto disponível (free full text), período de publicação (10 years), estudos realizados com humanos, nos idiomas inglês, espanhol e português, e idade (child: birth-18 years). Foram selecionados 1.281 artigos: 740 artigos disponíveis com o termo food insecurity, 258 food insecurity, 278 food AND insecurity, por fim, três artigos com human rigth to adequate food e dois artigos com human rigths dimensions of food.

Os critérios de inclusão adotados para a revisão integrativa foram: 1) ser artigo original advindo de estudo empírico; 2) ter sido publicado no período de 2007 a 2016; 3) ter sido realizado em cenário urbano; 4) incluir na população de investigação crianças e/ou adolescentes não institucionalizados.

Na Etapa 2 (Figura 1) foi realizada a revisão manual, com leitura dos títulos e resumos dos 1.281 artigos segundo os critérios de inclusão. Permaneceram na seleção 655 artigos. Dentre esses 655 artigos, foi feita a checagem dos critérios de inclusão e foram mantidos na seleção 169 artigos, quando foi realizado o download e leitura completa dos métodos. Houve a exclusão de 89 artigos: 25 por serem artigos de revisão, validação ou aprimoramento de escala para medir a IAN e avaliação de programas, e 64 artigos por serem estudos que mencionavam crianças e adolescentes no resumo, embora as análises tenham sido realizadas apenas com adultos. Além disso, não permaneceram na revisão artigos com comunidades tradicionais de pescadores, quilombolas e indígenas, área rural e restaurantes populares.

Assim, permaneceram na Etapa 3 (Figura 1) 80 artigos para leitura completa e extração dos dados. Dos 80 artigos foram extraídos os seguintes conteúdos para análise: ano de publicação; autores; títulos; as temáticas presentes nos títulos dos artigos; a abordagem metodológica do estudo; os países onde o estudo foi realizado; os cenários urbanos de investigação; os métodos utilizados para avaliação da situação de IAN; os aspectos relacionados a IAN descritos nos resultados; as conclusões e recomendações dos estudos.

$\mathrm{Na}$ organização e sumarização dos dados utilizou-se a elaboração de planilhas no Microsoft Excel 2010 e também foram realizadas análises estatísticas, com a produção de frequências e gráficos. Para a análise qualitativa de conteúdo foram feitas leituras sistemáticas e codificações para o agrupamento dos conteúdos semelhantes, bem como identificação das diferenças ou 


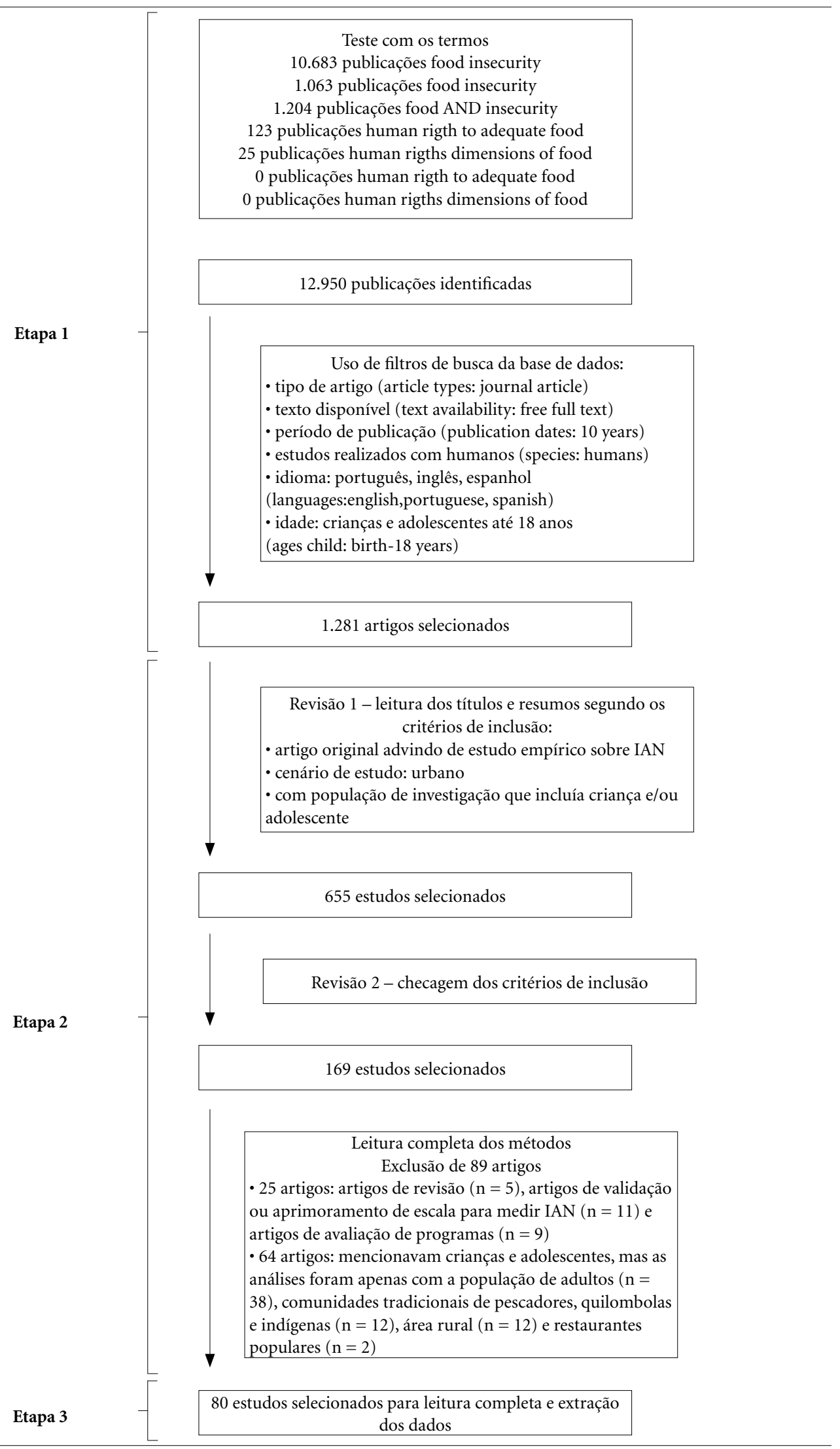

Figura 1. Etapas da busca bibliográfica dos artigos que compuseram a revisão integrativa. Base de dados PubMed, 2007-2016. 
relações circulantes que descrevem o fenômeno estudado ${ }^{19}$.

O marco conceitual que norteou a análise dos dados teve como base o conceito do direito humano à alimentação adequada utilizado em documentos internacionais da Organização das $\mathrm{Na}$ ções Unidas ${ }^{20,21}: O$ direito à alimentação adequada realiza-se quando cada homem, mulher e criança, sozinho ou em companhia de outros, tem acesso físico e econômico, ininterruptamente, à alimentação adequada ou aos meios para sua obtenção. O direito à alimentação adequada não deverá, portanto, ser interpretado em um sentido estrito ou restritivo, que o equaciona em termos de um pacote mínimo de calorias, proteínas e outros nutrientes específicos. $O$ direito à alimentação adequada terá de ser resolvido de maneira progressiva. No entanto, os Estados têm a obrigação precípua de implementar as ações necessárias para mitigar e aliviar a fome mesmo em épocas de desastres, naturais ou não.

\section{Resultados}

Dos 80 artigos, observou-se que 55 foram conduzidos em países do continente americano, 33 na América do Norte e 22 na América Latina e Caribe. Dentre esses 22 artigos com investigação conduzida na América Latina e Caribe, 15 foram realizados no Brasil, nas Regiões Nordeste ( $\mathrm{n}=$ $4)$, Sul $(\mathrm{n}=3)$, Sudeste $(\mathrm{n}=1)$, Centro-Oeste ( $\mathrm{n}$ $=1$ ) e seis tinham abrangência nacional ou foram realizados em duas ou mais regiões.

O segundo continente com maior expressão de artigos $(\mathrm{n}=13)$ foi a África, seguido da Ásia ( $\mathrm{n}$ $=4)$, Europa $(\mathrm{n}=3)$ e Oceania $(\mathrm{n}=1)$.

Dos 80 artigos, quatro eram estudos multicêntricos realizados na África e Ásia $(\mathrm{n}=1)$, América do Norte e África $(\mathrm{n}=1)$, Europa, América do Norte e Ásia $(\mathrm{n}=1)$, América Latina e Caribe e América do Norte $(\mathrm{n}=1)$.

Nos títulos dos artigos foram identificadas 18 temáticas emergentes (Figura 2). A temática mais presente foi a que relacionava a IAN com diversos aspectos demográficos, socioeconômicos e condições de moradia $(n=16)$; seguida daquelas que relacionavam a IAN ao estado nutricional ( $\mathrm{n}$ $=15)$ e ao consumo alimentar $(\mathrm{n}=10)$.

A maior diversidade temática segundo a origem geográfica dos estudos foi encontrada em países da América do Norte (Canadá e Estados Unidos), seguidos da América Latina e Caribe, e África (Figura 2).

Os estudos realizados em países da América Latina e Caribe abordaram temáticas como carências nutricionais, iniquidades em saúde, absenteísmo escolar, parasitose e amamentação. Apesar da diversidade temática encontrada nesses estudos, não estiveram presentes assuntos importantes, como saúde mental, HIV/Aids, gênero, doenças crônicas não transmissíveis, favelas, imigrantes, negros, saúde bucal e o direito humano à alimentação adequada. Essas temáticas foram identificadas com maior frequência em estudos conduzidos na América do Norte e na África (Figura 2).

Nos 15 estudos realizados no Brasil, as temáticas presentes foram estado nutricional $(\mathrm{n}=$ $6)$, IAN e diversos aspectos associados $(n=3)$, carências nutricionais $(\mathrm{n}=2)$, iniquidades em saúde $(\mathrm{n}=2)$, amamentação $(\mathrm{n}=1)$ e consumo alimentar $(\mathrm{n}=1)$ (Figura 2).

Os 80 artigos analisados foram publicados, principalmente, nos anos de $2009(\mathrm{n}=11), 2012$ $(\mathrm{n}=15), 2013(\mathrm{n}=12)$ e $2014(\mathrm{n}=15)$. O período de 2012 a 2014 foi o momento de maior publicação, significando 53\% do total dos artigos analisados $(\mathrm{n}=42)$.

Os artigos mostraram que os cenários urbanos comumente pesquisados para conhecer a situação de IAN são os domicílios $(\mathrm{n}=53)$, porém observaram-se outros cenários de investigação, como serviços de saúde (ambulatórios; $\mathrm{n}=7$ e hospitais; $n=5)$, escolas públicas $(n=9)$, creches públicas $(\mathrm{n}=1)$ e o conjunto destes cenários, como domicílios e escolas $(\mathrm{n}=2)$, domicílios e serviços de saúde $(\mathrm{n}=2)$, domicílios e ambiente social $(\mathrm{n}=1)$.

A abordagem metodológica dos estudos foi predominante quantitativa, sendo que 75 eram de abordagem quantitativa (94\%) e cinco de abordagem qualitativa (6\%).

Os cinco estudos qualitativos utilizaram para a produção dos dados: grupos focais $(n=2)$, entrevistas semi-estruturadas $(\mathrm{n}=1)$, intervenção educativa $(n=1)$ e o conjunto de técnicas como grupos focais e entrevistas semi-estruturadas (n $=1$ ). Os estudos qualitativos foram conduzidos em países da América Latina e Caribe (Argentina e Venezuela; $\mathrm{n}=2$ ) e América do Norte (Estados Unidos da América; $\mathrm{n}=2$ ) e Ásia (Irã; $\mathrm{n}=1$ ) (Quadro 1).

Os estudos com abordagem qualitativa avaliaram a situação de IAN por meio de roteiros próprios, com base no conteúdo da escala do Departamento de Agricultura dos Estados Unidos (USDA). Esses estudos mostraram o seu potencial de investigação para tratar de questões ligadas ao reconhecimento da IAN, como as experiências vividas pelas pessoas, os sofrimentos 


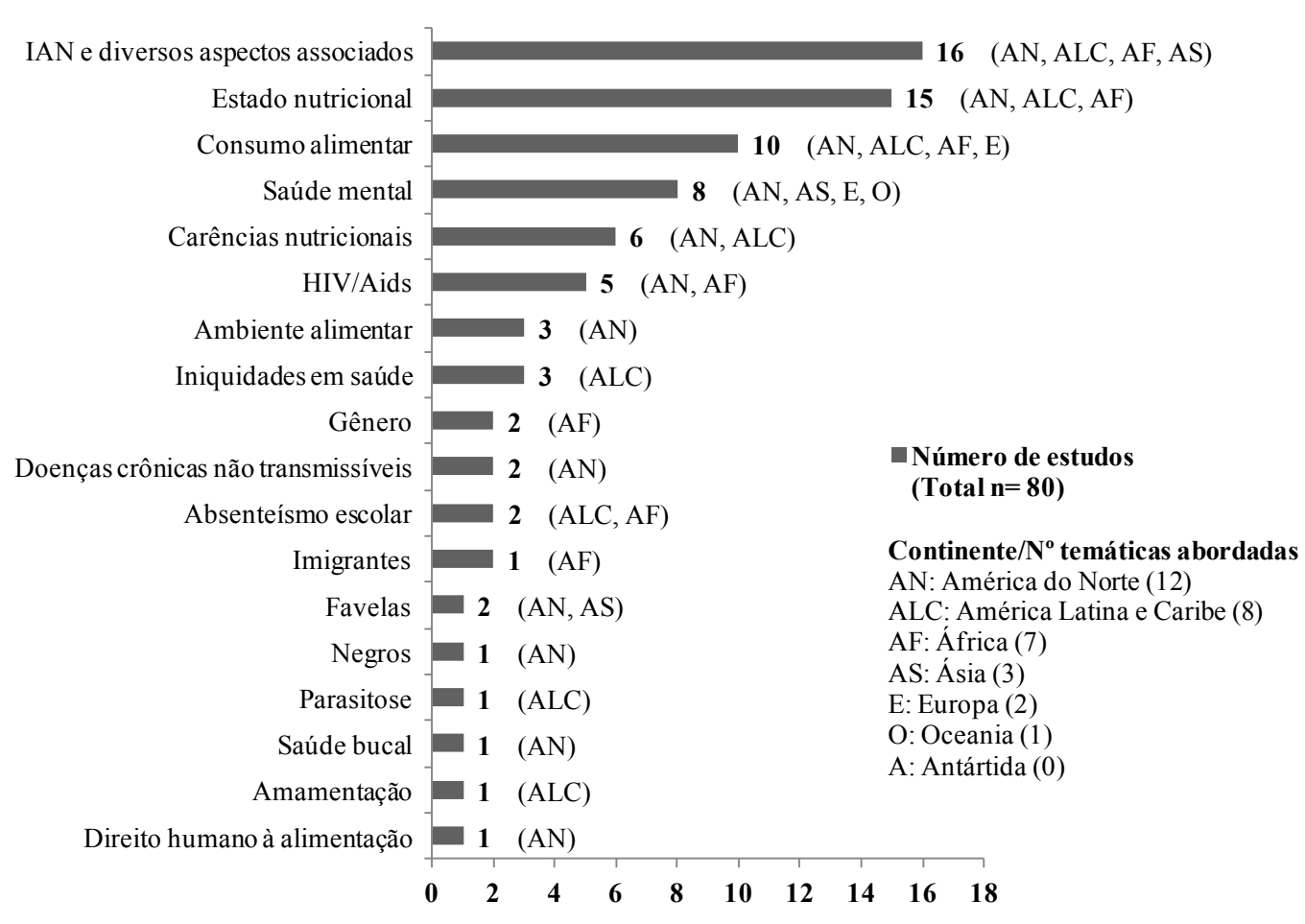

Figura 2. Temáticas emergentes identificadas nos 80 artigos e origem geográfica dos estudos. Base de dados PubMed, período 2007 - 2016.

emocionais sentidos, como angústia e tristeza quando a quantidade e a qualidade da ingestão de alimentos foram reduzidas, quando não se tinha recursos financeiros para a aquisição de alimentos ou precisavam comprar alimentos baratos com baixa qualidade nutricional. Além disso, mostraram o que as pessoas vivenciavam quando a situação de IAN se instalava, por exemplo, a realização de refeições menores, o reconhecimento da fome, da magreza ou o excesso de peso, a piora da situação de saúde, a presença de violência no domicílio, o consumo de alimentos oriundos do lixo encontrado na rua e o trabalho infantil, como estratégias para auxiliar no enfrentamento da situação de IAN.

Dos 75 estudos quantitativos analisados, 26 eram de seguimentos longitudinais ligados à pesquisas nacionais ou coorte (Quadro 2) e 49 eram estudos transversais epidemiológicos (Quadro 3), ambos conduzidos em países dos diversos continentes.

Para avaliar a situação de IAN, os estudos com abordagem quantitativa utilizaram como instrumento para a produção dos dados, questionários estruturados em forma de escalas psicométricas, tendo como base a escala do Departamento de Agricultura dos Estados Unidos (USDA), a Household Food Security Survey Module - HFSSM.

Os estudos quantitativos com base na escala do USDA desenvolveram suas próprias escalas adaptadas. Para as adaptações foram consideradas variações das realidades locais, como as culturais de linguagem. Com o intuito de verificar a adaptação das perguntas da escala para cada realidade e população, os estudos quantitativos se utilizaram de análises estatísticas, como o cálculo do coeficiente $\alpha$ de Cronbach para medir a confiabilidade psicométrica da escala por meio da análise de consistência interna, com variação do de Cronbach entre 0,70 a 0,90 , que segundo os estudos demonstrava uma boa qualidade da escala para a mensuração da IAN.

Esse tipo de avaliação, por meio de escala de perguntas, tem o objetivo de abordar, prioritariamente, temas centrais como a quantidade, a qualidade alimentar e a percepção de incertezas relacionadas à alimentação. Os estudos analisados mostraram alguns exemplos dessas escalas adaptadas, como a Colombian Househould Food Scurity Scale - CHSS, a Escala Brasileira de In- 
Quadro 1. Focos temáticos e estratégias para atuação em SAN extraídos, respectivamente, das conclusões e recomendações dos estudos com abordagem qualitativa $(\mathrm{n}=5$ ). Base de dados PubMed, 2007-2016.

\begin{tabular}{|c|c|c|c|c|c|}
\hline $\begin{array}{l}\text { Focos } \\
\text { temáticos }\end{array}$ & $\begin{array}{c}\text { Autor/Ano } \\
\text { Continente/ } \\
\text { país }\end{array}$ & Cenário & $\begin{array}{l}\text { Aspectos } \\
\text { relacionados }\end{array}$ & Conclusões & $\begin{array}{c}\text { Recomendações/Estratégias } \\
\text { de ação }\end{array}$ \\
\hline \begin{tabular}{|l} 
Sistemas \\
alimentares
\end{tabular} & $\begin{array}{l}\text { Dastgiri S et al., } \\
2011 \\
\text { Ásia (Irã) }\end{array}$ & $\begin{array}{l}\text { intervenção } \\
\text { educativa; } \\
\text { domicílios }\end{array}$ & $\begin{array}{l}\text { demográficos e } \\
\text { socioeconômicos }\end{array}$ & $\begin{array}{l}\text { Há necessidade } \\
\text { urgente de } \\
\text { colaboração } \\
\text { entre lideranças } \\
\text { governamentais, } \\
\text { internacional } \\
\text { e local, para } \\
\text { identificar e } \\
\text { implementar } \\
\text { programas de } \\
\text { intervenção para } \\
\text { superar a IAN. }\end{array}$ & $\begin{array}{l}\text { Considerar o sistema } \\
\text { político para a construção } \\
\text { de um modelo de saúde } \\
\text { pública para controlar na } \\
\text { região a IAN enquanto um } \\
\text { problema de saúde. }\end{array}$ \\
\hline $\begin{array}{l}\text { Pobreza e } \\
\text { condições } \\
\text { de renda }\end{array}$ & $\begin{array}{l}\text { Bernal J et al., } \\
2016 \\
\text { América } \\
\text { Latina e Caribe } \\
\text { (Venezuela) }\end{array}$ & $\begin{array}{l}\text { grupos focais } \\
\text { e entrevistas } \\
\text { semiestruturadas; } \\
\text { escolas públicas }\end{array}$ & $\begin{array}{l}\text { cognitivos, } \\
\text { emocionais; } \\
\text { quantidade e } \\
\text { qualidade da } \\
\text { ingestão de } \\
\text { alimentos e } \\
\text { magreza }\end{array}$ & $\begin{array}{l}\text { Crianças em IAN } \\
\text { reconheceram } \\
\text { a redução da } \\
\text { qualidade e } \\
\text { quantidade de } \\
\text { alimentos, o } \\
\text { sacrifício do } \\
\text { consumo de } \\
\text { comida e de } \\
\text { comida do lixo, } \\
\text { e informaram } \\
\text { trabalho infantil } \\
\text { como estratégia } \\
\text { para compra dos } \\
\text { alimentos }\end{array}$ & $\begin{array}{l}\text { Investigação e políticas } \\
\text { para entender e direcionar } \\
\text { a distribuição de } \\
\text { benefícios para crianças, } \\
\text { que visam garantir o seu } \\
\text { desenvolvimento físico, } \\
\text { cognitivo e bem-estar sócio } \\
\text { emocional. }\end{array}$ \\
\hline \multirow[t]{2}{*}{$\begin{array}{l}\text { Ambiente } \\
\text { social e } \\
\text { ambiente } \\
\text { alimentar }\end{array}$} & $\begin{array}{l}\text { Lindsay AC et } \\
\text { al., } 2012 \\
\text { América } \\
\text { Latina e Caribe } \\
\text { (Argentina) }\end{array}$ & $\begin{array}{l}\text { grupos focais; } \\
\text { serviço de saúde } \\
\text { hospitalar }\end{array}$ & $\begin{array}{l}\text { baixa renda, } \\
\text { trabalho, } \\
\text { preocupações } \\
\text { financeiras, } \\
\text { práticas } \\
\text { alimentares }\end{array}$ & $\begin{array}{l}\text { Domicílios em } \\
\text { IAN apresentam } \\
\text { dificuldades } \\
\text { na criação de } \\
\text { um ambiente } \\
\text { de alimentos } \\
\text { saudáveis para } \\
\text { seus filhos }\end{array}$ & $\begin{array}{l}\text { Intervenções em saúde } \\
\text { pública e intervenções em } \\
\text { IAN que visam o direito à } \\
\text { alimentação saudável são } \\
\text { fundamentais para o respeito } \\
\text { e preservação dos valores } \\
\text { culturais relacionados aos } \\
\text { hábitos alimentares. }\end{array}$ \\
\hline & \begin{tabular}{|l} 
Fram MS et al., \\
2011 \\
América do \\
Norte (EUA)
\end{tabular} & $\begin{array}{l}\text { entrevistas semi- } \\
\text { estruturadas; } \\
\text { domicílio }\end{array}$ & $\begin{array}{l}\text { experiências } \\
\text { cognitivas, } \\
\text { emocionais e } \\
\text { físicas }\end{array}$ & $\begin{array}{l}\text { O ambiente social } \\
\text { e alimentar são } \\
\text { espaços potenciais } \\
\text { de qualidade para } \\
\text { as interações entre } \\
\text { crianças e pais }\end{array}$ & $\begin{array}{l}\text { O esforço para acabar } \\
\text { com a fome de crianças } \\
\text { deve ter como base uma } \\
\text { compreensão abrangente de } \\
\text { experiências de IAN a partir } \\
\text { da perspectiva da criança, } \\
\text { em termo de conteúdo e } \\
\text { contexto. }\end{array}$ \\
\hline $\begin{array}{l}\text { Consumo } \\
\text { alimentar }\end{array}$ & $\begin{array}{l}\text { Widome R et } \\
\text { al., } 2009 \\
\text { América do } \\
\text { Norte (EUA) }\end{array}$ & $\begin{array}{l}\text { grupos focais; } \\
\text { domicílio e escola }\end{array}$ & \begin{tabular}{|l} 
hábitos \\
alimentares, \\
percepções \\
e ingestão \\
alimentar
\end{tabular} & $\begin{array}{l}\text { Os padrões } \\
\text { alimentares dos } \\
\text { adolescentes em } \\
\text { IAN diferem } \\
\text { em aspectos } \\
\text { importantes } \\
\text { dos padrões } \\
\text { alimentares dos } \\
\text { que estão em SAN }\end{array}$ & $\begin{array}{l}\text { O esforço para educar } \\
\text { adolescentes em IAN deve } \\
\text { eliminar as barreiras para } \\
\text { uma alimentação saudável. } \\
\text { Políticas e intervenções } \\
\text { focadas na melhoria dos } \\
\text { alimentos. }\end{array}$ \\
\hline
\end{tabular}

[grifo nosso] 
Quadro 2. Focos temáticos e estratégias para atuação em SAN extraídos, respectivamente, das conclusões e recomendações dos estudos longitudinais com abordagem quantitativa $(n=26)$. Base de dados PubMed, 2007-2016.

\begin{tabular}{|c|c|c|c|c|c|}
\hline Focos temáticos & $\begin{array}{l}\text { Autor/Ano } \\
\text { Continente/ } \\
\text { país }\end{array}$ & Cenário & $\begin{array}{c}\text { Aspectos } \\
\text { relacionados }\end{array}$ & Conclusões & $\begin{array}{c}\text { Recomendações/ } \\
\text { Estratégias de ação }\end{array}$ \\
\hline $\begin{array}{l}\text { Sistemas } \\
\text { alimentares } \\
(\mathrm{n}=1)\end{array}$ & $\begin{array}{l}\text { Zhang Q et } \\
\text { al., } 2013 \\
\text { América do } \\
\text { Norte (EUA) }\end{array}$ & domicílios & $\begin{array}{l}\text { preço dos } \\
\text { alimentos }\end{array}$ & $\begin{array}{l}\text { Estratégias de controle } \\
\text { de preços dos } \\
\text { alimentos: eliminação } \\
\text { de subsídios e } \\
\text { imposição de impostos, } \\
\text { impactam no aumento } \\
\text { do preço dos alimentos } \\
\text { e na capacidade das } \\
\text { famílias de garantirem } \\
\text { uma dieta adequada e } \\
\text { de alta qualidade. }\end{array}$ & $\begin{array}{l}\text { Planejamento e a } \\
\text { coordenação cuidadosa } \\
\text { de estratégias de } \\
\text { políticas públicas, } \\
\text { políticas de preço dos } \\
\text { alimentos podem ser } \\
\text { benéficos à saúde e à } \\
\text { SAN. }\end{array}$ \\
\hline $\begin{array}{l}\text { Desastres } \\
\text { naturais } \\
(\mathrm{n}=1)\end{array}$ & $\begin{array}{l}\text { Hutson RA et } \\
\text { al., } 2014 \\
\text { América } \\
\text { Latina e } \\
\text { Caribe (Haiti) }\end{array}$ & domicílios & $\begin{array}{l}\text { escolaridade, } \\
\text { situação de saúde, } \\
\text { violação de } \\
\text { direitos humanos } \\
\text { e histórias de } \\
\text { violência na } \\
\text { família }\end{array}$ & $\begin{array}{l}\text { Desastres naturais } \\
\text { influenciam na situação } \\
\text { de IAN. }\end{array}$ & $\begin{array}{l}\text { Realização de estudos } \\
\text { de coorte em locais com } \\
\text { altas probabilidades } \\
\text { de desastres naturais } \\
\text { ou de origem humana. } \\
\text { Melhores orientações } \\
\text { e prestação de serviços } \\
\text { essenciais, ir além da } \\
\text { vulnerabilidade e da } \\
\text { vitimização. }\end{array}$ \\
\hline \multirow[t]{2}{*}{$\begin{array}{l}\text { Pobreza e } \\
\text { condições de } \\
\text { renda } \\
(\mathrm{n}=2)\end{array}$} & $\begin{array}{l}\text { Belachew T et } \\
\text { al., } 2012 \\
\text { África } \\
\text { (Etiópia) }\end{array}$ & domicílios & $\begin{array}{l}\text { baixa renda, baixa } \\
\text { escolaridade, } \\
\text { gênero }\end{array}$ & $\begin{array}{l}\text { Adolescentes de áreas } \\
\text { urbanas que membros } \\
\text { de famílias de renda } \\
\text { baixa estão em maior } \\
\text { risco de IAN crônica, } \\
\text { essa situação produz } \\
\text { uma diminuição do } \\
\text { poder de compra de } \\
\text { alimentos }\end{array}$ & $\begin{array}{l}\text { Intervenções de SAN, } \\
\text { incluindo uma rede de } \\
\text { segurança e programa } \\
\text { de estabilização do } \\
\text { mercado devem ser } \\
\text { realizados para a redução } \\
\text { do grau de IAN crônica } \\
\text { entre os adolescentes. }\end{array}$ \\
\hline & $\begin{array}{l}\text { Chen L et al., } \\
2009 \\
\text { Ásia (Taiwan) }\end{array}$ & \begin{tabular}{|l|} 
serviço \\
de saúde \\
ambulatorial
\end{tabular} & $\begin{array}{l}\text { doenças } \\
\text { associadas à } \\
\text { nutrição (diabetes, } \\
\text { desordens } \\
\text { metabólicas, } \\
\text { anemia), } \\
\text { crescimento, } \\
\text { desordens mentais }\end{array}$ & $\begin{array}{l}\text { A pobreza e a IAN } \\
\text { podem formar um ciclo } \\
\text { vicioso, causar mais } \\
\text { privação de riqueza } \\
\text { através de encargos } \\
\text { com despesas diretas } \\
\text { para cuidado de saúde } \\
\text { e custos indiretos } \\
\text { associados a perda de } \\
\text { produtividade. }\end{array}$ & $\begin{array}{l}\text { Garantir a SAN para } \\
\text { crianças é uma das } \\
\text { mais importantes } \\
\text { responsabilidades } \\
\text { de um governo. } \\
\text { Outras abordagens } \\
\text { de programas podem } \\
\text { ser necessárias para a } \\
\text { superação da situação de } \\
\text { IAN de crianças pobres e } \\
\text { dos resultados de saúde } \\
\text { relacionados. }\end{array}$ \\
\hline
\end{tabular}

continua

segurança Alimentar - EBIA e a Latin American and Caribean Food Security Scale - ELCSA.

A partir dos 80 artigos foi possível identificar 36 aspectos relacionados à situação de IAN, que abarcavam questões demográficas (idade, sexo, cor da pele); socioeconômicas (escolaridade, classe econômica, renda); aculturação (lo- cal de nascimento e identificação linguística); composição familiar (número de residentes, número de crianças no domicílio); crescimento infantil; estado nutricional (desnutrição, sobrepeso, obesidade; déficit de estatura para a idade); desempenho escolar; amamentação (práticas e percepções); morbidades (diabetes, desordens 
Quadro 2. Focos temáticos e estratégias para atuação em SAN extraídos, respectivamente, das conclusões e recomendações dos estudos longitudinais com abordagem quantitativa $(n=26)$. Base de dados PubMed, 2007-2016.

\begin{tabular}{|c|c|c|c|c|c|}
\hline Focos temáticos & $\begin{array}{c}\text { Autor/Ano } \\
\text { Continente/ } \\
\text { país }\end{array}$ & Cenário & $\begin{array}{c}\text { Aspectos } \\
\text { relacionados }\end{array}$ & Conclusões & $\begin{array}{c}\text { Recomendações/ } \\
\text { Estratégias de ação }\end{array}$ \\
\hline $\begin{array}{l}\text { Grupos mais } \\
\text { vulneráveis à } \\
\text { IAN } \\
(\mathrm{n}=1)\end{array}$ & $\begin{array}{l}\text { Chilton M et } \\
\text { al., } 2009 \\
\text { América do } \\
\text { Norte (EUA) }\end{array}$ & $\begin{array}{l}\text { serviço } \\
\text { de saúde } \\
\text { hospitalar }\end{array}$ & $\begin{array}{l}\text { condições de } \\
\text { saúde }\end{array}$ & $\begin{array}{l}\text { Crianças de mães } \\
\text { imigrantes estão em } \\
\text { maior risco de saúde e } \\
\text { IAN. O estado de saúde } \\
\text { na infância afeta, não só } \\
\text { o desenvolvimento de } \\
\text { saúde, desenvolvimento, } \\
\text { estado socioemocional } \\
\text { e desempenho escolar, } \\
\text { o estado de saúde } \\
\text { do adulto, o nível } \\
\text { socioeconômico e a } \\
\text { produtividade. Políticas } \\
\text { que restrigem o } \\
\text { acesso das famílias de } \\
\text { imigrantes aos cuidados } \\
\text { de saúde, podem ter } \\
\text { efeitos graves sobre esta } \\
\text { população já vulnerável. }\end{array}$ & $\begin{array}{l}\text { Intervenções políticas } \\
\text { de combate à IAN em } \\
\text { famílias de imigrantes } \\
\text { podem promover a } \\
\text { saúde de crianças. }\end{array}$ \\
\hline \multirow[t]{2}{*}{$\begin{array}{l}\text { Gênero } \\
(\mathrm{n}=2)\end{array}$} & $\begin{array}{l}\text { Belachew T et } \\
\text { al., } 2011 \\
\text { África } \\
\text { (Etiópia) }\end{array}$ & domicílio & gênero & $\begin{array}{l}\text { Na situação de } \\
\text { IAN, o gênero é um } \\
\text { importante preditor } \\
\text { do estado de saúde } \\
\text { auto-relatado pelo } \\
\text { adolescente }\end{array}$ & $\begin{array}{l}\text { Intervenções de SAN } \\
\text { devem prestar atenção } \\
\text { especial às meninas para } \\
\text { diminuir as diferenças de } \\
\text { saúde entre meninos e } \\
\text { meninas }\end{array}$ \\
\hline & $\begin{array}{l}\text { Hadley C et } \\
\text { al., } 2008 \\
\text { África } \\
\text { (Etiópia) }\end{array}$ & domicílios & gênero & $\begin{array}{l}\text { A IAN na adolescência } \\
\text { está associada a } \\
\text { importantes dimensões } \\
\text { da saúde e bem- estar e } \\
\text { gênero. }\end{array}$ & $\begin{array}{l}\text { Pesquisas futuras para } \\
\text { verificar e examinar os } \\
\text { mecanismos pelos quais } \\
\text { meninas experimentam } \\
\text { maiores níveis de IAN } \\
\text { quando vivem em } \\
\text { domicílios com estresse } \\
\text { alimentar. }\end{array}$ \\
\hline $\begin{array}{l}\text { Ambiente social } \\
\text { e ambiente } \\
\text { alimentar } \\
(\mathrm{n}=1)\end{array}$ & $\begin{array}{l}\text { Carter MA et } \\
\text { al., } 2012 \\
\text { América } \\
\text { do Norte } \\
\text { (Canadá) }\end{array}$ & $\begin{array}{l}\text { domicílio } \\
\text { e ambiente } \\
\text { social }\end{array}$ & $\begin{array}{l}\text { aspectos do } \\
\text { ambiente social }\end{array}$ & $\begin{array}{l}\text { Abordar o ambiente } \\
\text { social em q as pessoas } \\
\text { vivem e a melhoria da } \\
\text { situação de renda do } \\
\text { agregado familiar pode } \\
\text { ser benéfico para o } \\
\text { enfrentamento da IAN. }\end{array}$ & $\begin{array}{l}\text { Mais estudos sobre } \\
\text { ambiente social locais. } \\
\text { Planejadores urbanos, } \\
\text { políticos, nutricionistas, } \\
\text { assistentes sociais, } \\
\text { promotores de saúde } \\
\text { podem considerar } \\
\text { ambientes sociais locais } \\
\text { na implementação } \\
\text { de qualquer tipo } \\
\text { de intervenção em } \\
\text { SAN: iniciativas de } \\
\text { capacitação para } \\
\text { construir capital social } \\
\text { e incentivar a interação } \\
\text { social na comunidade. } \\
\text { O planejamento e a } \\
\text { avaliação devem tornar- } \\
\text { se uma prioridade. }\end{array}$ \\
\hline
\end{tabular}


Quadro 2. Focos temáticos e estratégias para atuação em SAN extraídos, respectivamente, das conclusões e recomendações dos estudos longitudinais com abordagem quantitativa $(n=26)$. Base de dados PubMed, 2007-2016.

\begin{tabular}{|c|c|c|c|c|c|}
\hline Focos temáticos & $\begin{array}{c}\text { Autor/Ano } \\
\text { Continente/ } \\
\text { país }\end{array}$ & Cenário & $\begin{array}{l}\text { Aspectos } \\
\text { relacionados }\end{array}$ & Conclusões & $\begin{array}{l}\text { Recomendações/ } \\
\text { Estratégias de ação }\end{array}$ \\
\hline \multirow[t]{2}{*}{$\begin{array}{l}\text { Estado de Saúde } \\
(\mathrm{n}=2)\end{array}$} & $\begin{array}{l}\text { Ryu JH et al., } \\
2012 \\
\text { América do } \\
\text { Norte (EUA) }\end{array}$ & domicílio & estado de saúde & $\begin{array}{l}\text { Domicílios afetados } \\
\text { pela IAN podem ter } \\
\text { impacto negativo na } \\
\text { situação de saúde de } \\
\text { crianças. }\end{array}$ & $\begin{array}{l}\text { Apoio à programas de } \\
\text { assistência nutricional } \\
\text { à famílias vulneráveis, } \\
\text { programas de } \\
\text { alimentação escolar. }\end{array}$ \\
\hline & $\begin{array}{l}\text { Shaikh U et } \\
\text { al., } 2009 \\
\text { América do } \\
\text { Norte (EUA) }\end{array}$ & $\begin{array}{l}\text { domicílio e } \\
\text { serviço de } \\
\text { saúde }\end{array}$ & $\begin{array}{l}\text { suplementação } \\
\text { de vitaminas e } \\
\text { minerais }\end{array}$ & $\begin{array}{l}\text { Um grande } \mathrm{n}^{\circ} \text { de } \\
\text { crianças e adolescentes } \\
\text { usam suplementos } \\
\text { vitamínicos e minerais. }\end{array}$ & $\begin{array}{l}\text { Pesquisas qualitativas } \\
\text { para explorar a } \\
\text { importância relativa dos } \\
\text { fatores que influenciam } \\
\text { a decisão dos pais para } \\
\text { usarem suplementos } \\
\text { vitamínicos e minerais } \\
\text { para os filhos. }\end{array}$ \\
\hline \multirow[t]{4}{*}{$\begin{array}{l}\text { Saúde mental } \\
(\mathrm{n}=4)\end{array}$} & $\begin{array}{l}\text { McLaughlin } \\
\text { KA et al., } \\
2012 \\
\text { América do } \\
\text { Norte (EUA) }\end{array}$ & $\begin{array}{l}\text { domicílios e } \\
\text { escolas }\end{array}$ & saúde mental & $\begin{array}{l}\text { O acesso aos alimentos } \\
\text { em quantidade e } \\
\text { qualidade insuficentes } \\
\text { está associado a um } \\
\text { gama de desordens } \\
\text { mentais em } \\
\text { adolescentes. }\end{array}$ & $\begin{array}{l}\text { Expansão de programas } \\
\text { destinados à aliviar a } \\
\text { fome de crianças e a } \\
\text { pressão econômica das } \\
\text { famílias. }\end{array}$ \\
\hline & $\begin{array}{l}\text { Belsky DW } \\
\text { et al., } \\
2010 \\
\text { Europa, } \\
\text { Reino Unido, } \\
\text { Inglaterrra e } \\
\text { País de Gales }\end{array}$ & domicílios & $\begin{array}{l}\text { desenvolvimento } \\
\text { cognitivo, } \\
\text { comportamental e } \\
\text { emocional }\end{array}$ & $\begin{array}{l}\text { IAN associada a } \\
\text { problemas emocionais } \\
\text { de escolares. A } \\
\text { personalidade das } \\
\text { mães e a sensibilidade } \\
\text { doméstica às } \\
\text { necessidades das } \\
\text { crianças podem } \\
\text { apresentar desafios para } \\
\text { a IAN. }\end{array}$ & $\begin{array}{l}\text { Intervenções } \\
\text { para melhora na } \\
\text { parentalidade, } \\
\text { redução do abandono } \\
\text { e benefícios para } \\
\text { suprimento de alimento } \\
\text { nos domicílios. }\end{array}$ \\
\hline & $\begin{array}{l}\text { Huang J et al., } \\
2010 \\
\text { América do } \\
\text { Norte (EUA) }\end{array}$ & domicílios & $\begin{array}{l}\text { problemas } \\
\text { comportamentais }\end{array}$ & $\begin{array}{l}\text { Relações dinâmicas } \\
\text { entre IAN, } \\
\text { características dos } \\
\text { pais e problemas } \\
\text { comportamentais } \\
\text { da criança não são } \\
\text { capturadas de uma } \\
\text { forma simples. }\end{array}$ & $\begin{array}{l}\text { Essas relações devem ser } \\
\text { investigadas com dados } \\
\text { bem delineados e com } \\
\text { diversas metodologias }\end{array}$ \\
\hline & $\begin{array}{l}\text { Melchior M } \\
\text { et al., 2009 } \\
\text { Europa e } \\
\text { Reino Unido }\end{array}$ & domicílios & $\begin{array}{l}\text { problemas } \\
\text { comportamentais }\end{array}$ & $\begin{array}{l}\text { IAN mais frequente } \\
\text { em crianças de mães } \\
\text { com experiência } \\
\text { de problemas de } \\
\text { saúde mental, como } \\
\text { depressão, psicoses e } \\
\text { violência doméstica. }\end{array}$ & $\begin{array}{l}\text { Estudos de intervenção } \\
\text { para testar se melhorar } \\
\text { a saúde mental das mães } \\
\text { pode aliviar o impacto } \\
\text { da IAN em famílias com } \\
\text { crianças }\end{array}$ \\
\hline
\end{tabular}

metabólicas, anemia, diarreia, infecções respiratórias, parasitoses); acesso aos alimentos (preço, local de compra); saúde bucal (cárie); saúde mental; condições de saneamento; gênero; violações de direitos humanos; violência doméstica, entre outros (Quadros 1, 2 e 3). 
Quadro 2. Focos temáticos e estratégias para atuação em SAN extraídos, respectivamente, das conclusões e recomendações dos estudos longitudinais com abordagem quantitativa $(n=26)$. Base de dados PubMed, 2007-2016.

\begin{tabular}{|c|c|c|c|c|c|}
\hline Focos temáticos & $\begin{array}{c}\text { Autor/Ano } \\
\text { Continente/ } \\
\text { país } \\
\end{array}$ & Cenário & $\begin{array}{l}\text { Aspectos } \\
\text { relacionados }\end{array}$ & Conclusões & $\begin{array}{l}\text { Recomendações/ } \\
\text { Estratégias de ação }\end{array}$ \\
\hline \multirow[t]{3}{*}{$\begin{array}{l}\text { Estado } \\
\text { Nutricional } \\
(\mathrm{n}=3)\end{array}$} & $\begin{array}{l}\text { Gundersen C } \\
\text { et al., } 2009 \\
\text { América do } \\
\text { Norte (EUA) }\end{array}$ & domicílios & $\begin{array}{l}\text { estado nutricional } \\
\text { (obesidade) }\end{array}$ & $\begin{array}{l}\text { Crianças em situação } \\
\text { de IAN não foram } \\
\text { mais propensas a serem } \\
\text { obesas do que crianças } \\
\text { em situação de SAN, } \\
\text { após o controle de } \\
\text { outros fatores como } \\
\text { etnia e gênero. }\end{array}$ & $\begin{array}{l}\text { Manutenção de } \\
\text { programas de } \\
\text { enfrentamento da } \\
\text { obesidade infantil, como } \\
\text { atividade física nas } \\
\text { escolas e programas de } \\
\text { nutrição e qualidade de } \\
\text { vida. }\end{array}$ \\
\hline & $\begin{array}{l}\text { Gundersen C } \\
\text { et al., } 2008 \\
\text { América do } \\
\text { Norte (EUA) }\end{array}$ & domicílios & $\begin{array}{l}\text { estado nutrional } \\
\text { (sobrepeso) }\end{array}$ & $\begin{array}{l}\text { A IAN e o excesso de } \\
\text { peso coexistiram entre } \\
\text { adolescentes de baixa } \\
\text { renda. }\end{array}$ & $\begin{array}{l}\text { Pesquisas para } \\
\text { explorar as relações } \\
\text { potenciais entre a IAN } \\
\text { e o sobrepeso, além de } \\
\text { políticas para informar } \\
\text { melhor e tentar abordar } \\
\text { essas questões entre } \\
\text { famílias de baixa renda. }\end{array}$ \\
\hline & $\begin{array}{l}\text { Bronte- } \\
\text { Tinkew J et } \\
\text { al., } \\
2007 \\
\text { América do } \\
\text { Norte (EUA) }\end{array}$ & domicílios & $\begin{array}{l}\text { estado nutricional } \\
\text { (sobrepeso) }\end{array}$ & $\begin{array}{l}\text { A IAN interfere nas } \\
\text { interações entre } \\
\text { pais e filhos e afeta } \\
\text { aspectos centrais do } \\
\text { desenvolvimento, tais } \\
\text { como a saúde geral e o } \\
\text { excesso de peso. }\end{array}$ & $\begin{array}{l}\text { Continuidade e o } \\
\text { fortalecimento de } \\
\text { iniciativas políticas para } \\
\text { assegurar que famílias } \\
\text { com crianças tenham } \\
\text { comida suficiente, } \\
\text { previsível e confiável. }\end{array}$ \\
\hline $\begin{array}{l}\text { Carências } \\
\text { Nutricionais } \\
(\mathrm{n}=1)\end{array}$ & $\begin{array}{l}\text { Eicher-Miller } \\
\text { HA et al., } \\
2009 \\
\text { América do } \\
\text { Norte (EUA) }\end{array}$ & \begin{tabular}{|l|} 
serviço \\
de saúde \\
ambulatorial
\end{tabular} & $\begin{array}{l}\text { deficiência de } \\
\text { micronutriente - } \\
\text { ferro }\end{array}$ & $\begin{array}{l}\text { Anemia por deficiência } \\
\text { de ferro é uma } \\
\text { preocupação para } \\
\text { adolescentes em IAN, } \\
\text { apesar da existência de } \\
\text { políticas e programas } \\
\text { direcionados a este } \\
\text { público. }\end{array}$ & $\begin{array}{l}\text { Necessidade contínua } \\
\text { de intervenções para } \\
\text { reduzir a anemia } \\
\text { ferropriva entre crianças } \\
\text { com IAN e melhorar a } \\
\text { sua situação de SAN }\end{array}$ \\
\hline \multirow[t]{2}{*}{$\begin{array}{l}\text { Consumo } \\
\text { alimentar } \\
(\mathrm{n}=2)\end{array}$} & $\begin{array}{l}\text { Belachew T et } \\
\text { al., } 2013 \\
\text { África } \\
\text { (Etópia) }\end{array}$ & domicílios & $\begin{array}{l}\text { práticas } \\
\text { alimentares }\end{array}$ & $\begin{array}{l}\text { IAN tem consequência } \\
\text { negativa nas dietas } \\
\text { de adolescentes que } \\
\text { pode colocá-los em } \\
\text { risco de desenvolver } \\
\text { múltiplas deficiências } \\
\text { nutricionais. }\end{array}$ & $\begin{array}{l}\text { Programas para } \\
\text { melhorar a nutrição } \\
\text { na adolescência. } \\
\text { Intervenções de SAN } \\
\text { na produção local } \\
\text { diversificada e o } \\
\text { consumo de alimentos } \\
\text { ricos em nutrientes. }\end{array}$ \\
\hline & $\begin{array}{l}\text { Cunningham } \\
\text { TJ et al., } 2012 \\
\text { América do } \\
\text { Norte (EUA) }\end{array}$ & domicílios & $\begin{array}{l}\text { consumo de } \\
\text { refrigerantes }\end{array}$ & $\begin{array}{l}\text { A ingestão de } \\
\text { refrigerantes durante } \\
\text { a primeira infância, } \\
\text { um período sensível } \\
\text { do desenvolvimento } \\
\text { humano, pode } \\
\text { representar um } \\
\text { caminho crítico que } \\
\text { liga a IAN a saúde. }\end{array}$ & $\begin{array}{l}\text { Disponibilidade e } \\
\text { acessibilidade de } \\
\text { alimentos nutritivos } \\
\text { devem ser parte } \\
\text { integrante de estratégias } \\
\text { de intervenção às } \\
\text { famílias em IAN. } \\
\text { Envolver vários setores } \\
\text { de diferentes níveis } \\
\text { estaduais e municipais. }\end{array}$ \\
\hline
\end{tabular}


Quadro 2. Focos temáticos e estratégias para atuação em SAN extraídos, respectivamente, das conclusões e recomendações dos estudos longitudinais com abordagem quantitativa $(n=26)$. Base de dados PubMed, 2007-2016.

\begin{tabular}{|c|c|c|c|c|c|}
\hline Focos temáticos & \begin{tabular}{|c|} 
Autor/Ano \\
Continente/ \\
país \\
\end{tabular} & Cenário & $\begin{array}{c}\text { Aspectos } \\
\text { relacionados }\end{array}$ & Conclusões & $\begin{array}{c}\text { Recomendações/ } \\
\text { Estratégias de ação }\end{array}$ \\
\hline $\begin{array}{l}\text { Amamentação } \\
(\mathrm{n}=1)\end{array}$ & $\begin{array}{l}\text { Young SL et } \\
\text { al., } 2014 \\
\text { África } \\
\text { (Uganda) }\end{array}$ & $\begin{array}{l}\text { serviço } \\
\text { de saúde } \\
\text { hospitalar }\end{array}$ & $\begin{array}{l}\text { amamentação } \\
\text { e alimentação } \\
\text { complementar }\end{array}$ & $\begin{array}{l}\text { Crianças de domicílios } \\
\text { em IAN não têm } \\
\text { aleitamento materno } \\
\text { até o sexto mês }\end{array}$ & $\begin{array}{l}\text { A relação causal entre } \\
\text { IAN, HIV, desnutrição } \\
\text { materna e práticas de } \\
\text { alimentação infantil } \\
\text { deve ser mais explorada }\end{array}$ \\
\hline \multirow[t]{4}{*}{$\begin{array}{l}\text { Desenvolvimento } \\
\text { e crescimento } \\
\text { infantil } \\
(\mathrm{n}=4)\end{array}$} & $\begin{array}{l}\text { Hernandez } \\
\text { DC et al., } \\
2009 \\
\text { América do } \\
\text { Norte (EUA) }\end{array}$ & domicílios & $\begin{array}{l}\text { desenvolvimento } \\
\text { motor e cognitivo, } \\
\text { peso e estado de } \\
\text { saúde }\end{array}$ & $\begin{array}{l}\text { Crianças que residem } \\
\text { em domicílios em IAN } \\
\text { experimentam efeitos } \\
\text { negativos em seu } \\
\text { desenvolvimento }\end{array}$ & $\begin{array}{l}\text { Sensibilização e } \\
\text { assistência podem } \\
\text { diminuir impactos } \\
\text { imediatos da IAN sobre } \\
\text { o desenvolvimento da } \\
\text { criança }\end{array}$ \\
\hline & $\begin{array}{l}\text { Belachew T et } \\
\text { al., } 2011 \\
\text { África } \\
\text { (Etiópia) }\end{array}$ & domicílios & idade da menarca & $\begin{array}{l}\text { IAN associada ao } \\
\text { atraso da idade da } \\
\text { menarca, isso reflete } \\
\text { no desenvolvimento, } \\
\text { crescimento no estado } \\
\text { nutricional e bem-estar } \\
\text { de meninas. }\end{array}$ & Não havia. \\
\hline & $\begin{array}{l}\text { Pilgrim A et } \\
\text { al., } 2012 \\
\text { Europa } \\
\text { (Reino } \\
\text { Unido) }\end{array}$ & domicílios & $\begin{array}{l}\text { dieta e } \\
\text { composição } \\
\text { corporal }\end{array}$ & $\begin{array}{l}\text { A saúde e a dieta } \\
\text { relatadas pelos mais } \\
\text { pobres têm implicações } \\
\text { importantes para o } \\
\text { desenvolvimento e } \\
\text { saúde de crianças ao } \\
\text { longo da vida }\end{array}$ & Não havia. \\
\hline & $\begin{array}{l}\text { Belachew T et } \\
\text { al., } 2013 \\
\text { África } \\
\text { (Etiópia) }\end{array}$ & domicílios & $\begin{array}{l}\text { crescimento } \\
\text { infantil }\end{array}$ & $\begin{array}{l}\text { IAN associada } \\
\text { negativamente ao } \\
\text { crescimento linear, } \\
\text { especialmente de } \\
\text { meninas }\end{array}$ & $\begin{array}{l}\text { Intervenções } \\
\text { nutricionais para } \\
\text { promover o crescimento } \\
\text { e a quebra do ciclo } \\
\text { intergeracional } \\
\text { da desnutrição. } \\
\text { Combinação de } \\
\text { diferentes tipos } \\
\text { de políticas e } \\
\text { programas que } \\
\text { interfiram na condição } \\
\text { socioeconômica, a } \\
\text { promoção da igualdade } \\
\text { de gênero. Pesquisas } \\
\text { para ajudar a entender } \\
\text { essa relação entre IAN e } \\
\text { crescimento. }\end{array}$ \\
\hline $\begin{array}{l}\text { Desempenho } \\
\text { escolar } \\
(\mathrm{n}=1)\end{array}$ & $\begin{array}{l}\text { Belachew T et } \\
\text { al., } 2011 \\
\text { África } \\
\text { (Etiópia) }\end{array}$ & domicílios & $\begin{array}{l}\text { absenteísmo } \\
\text { escolar, } \\
\text { desempenho } \\
\text { escolar }\end{array}$ & $\begin{array}{l}\text { IAN afeta negativamnte } \\
\text { a frequência e o } \\
\text { desempenho escolar de } \\
\text { adolescentes. }\end{array}$ & $\begin{array}{l}\text { Intervenções na } \\
\text { escola que considerem } \\
\text { formas de aumentar } \\
\text { a frequência escolar } \\
\text { e mecanismos que } \\
\text { melhorem a dieta de } \\
\text { escolares }\end{array}$ \\
\hline
\end{tabular}

[grifo nosso] 


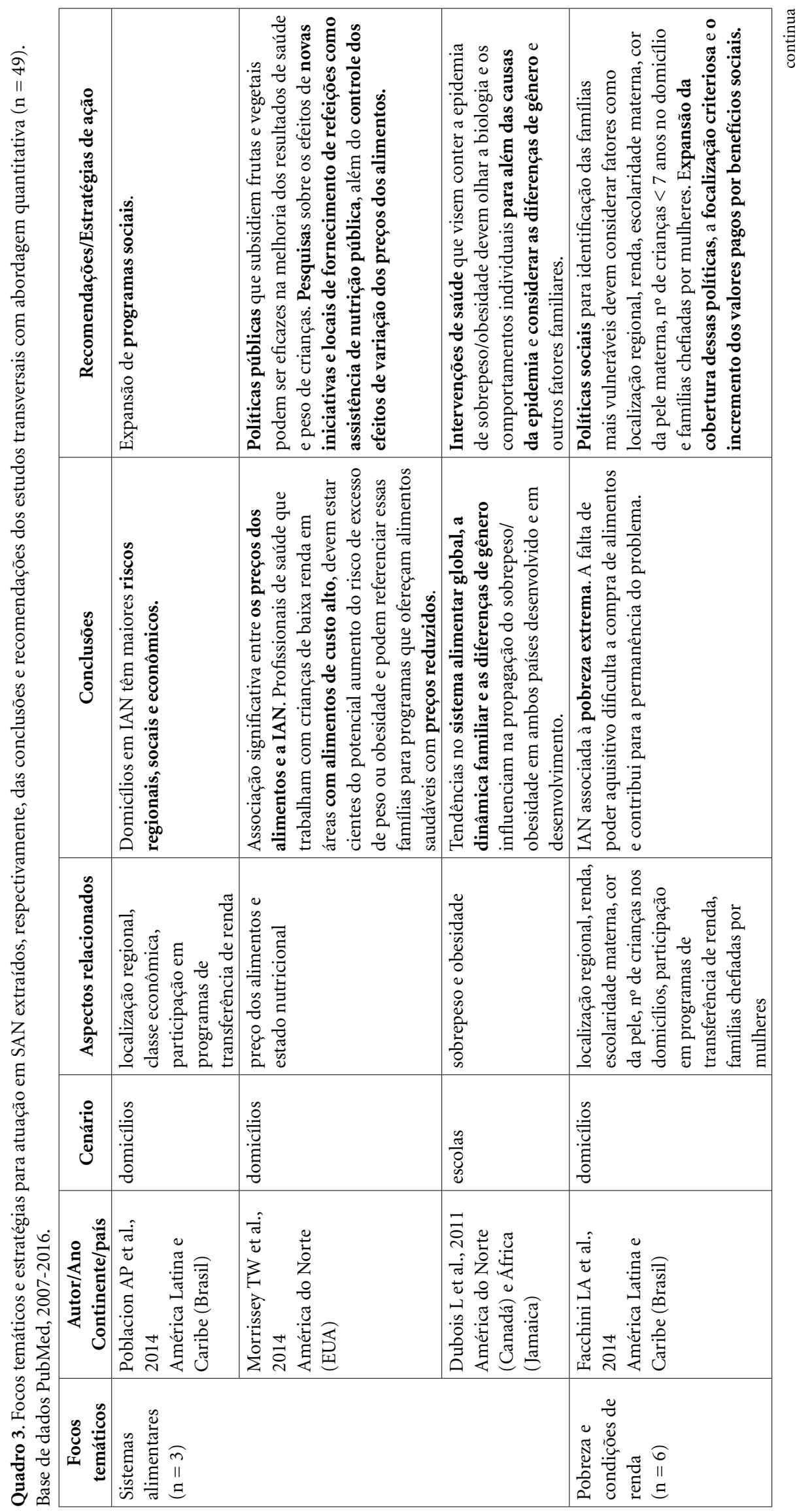




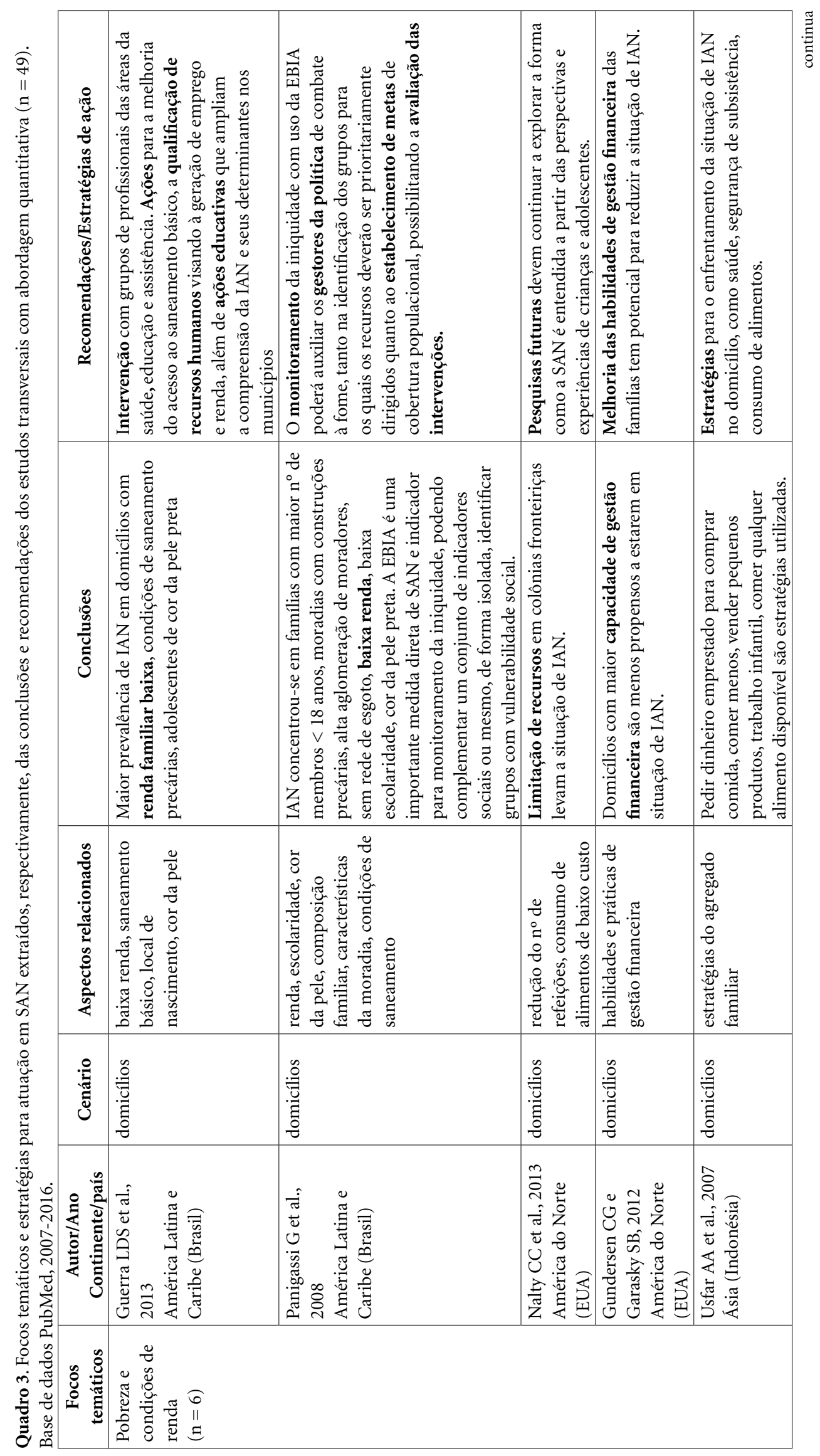




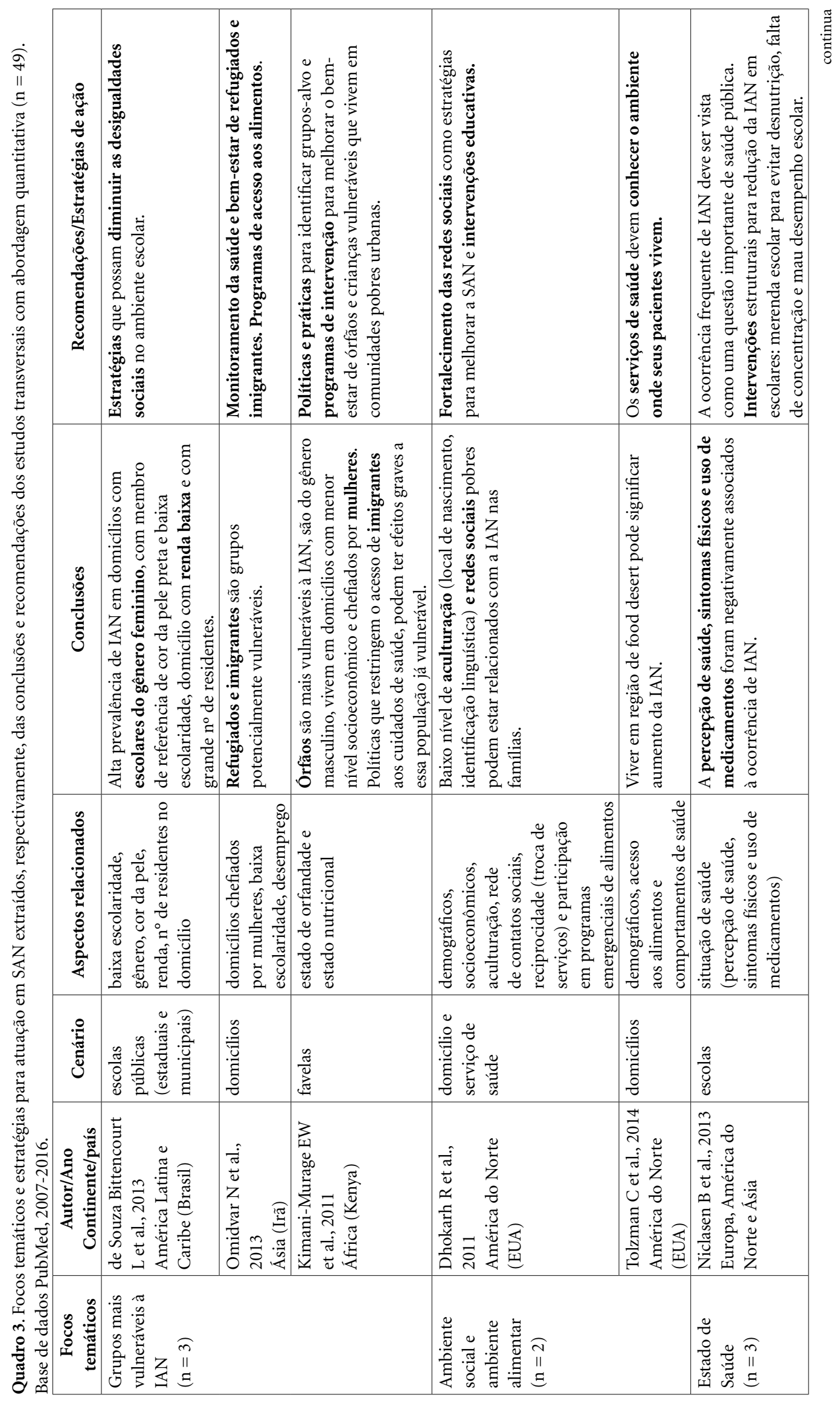




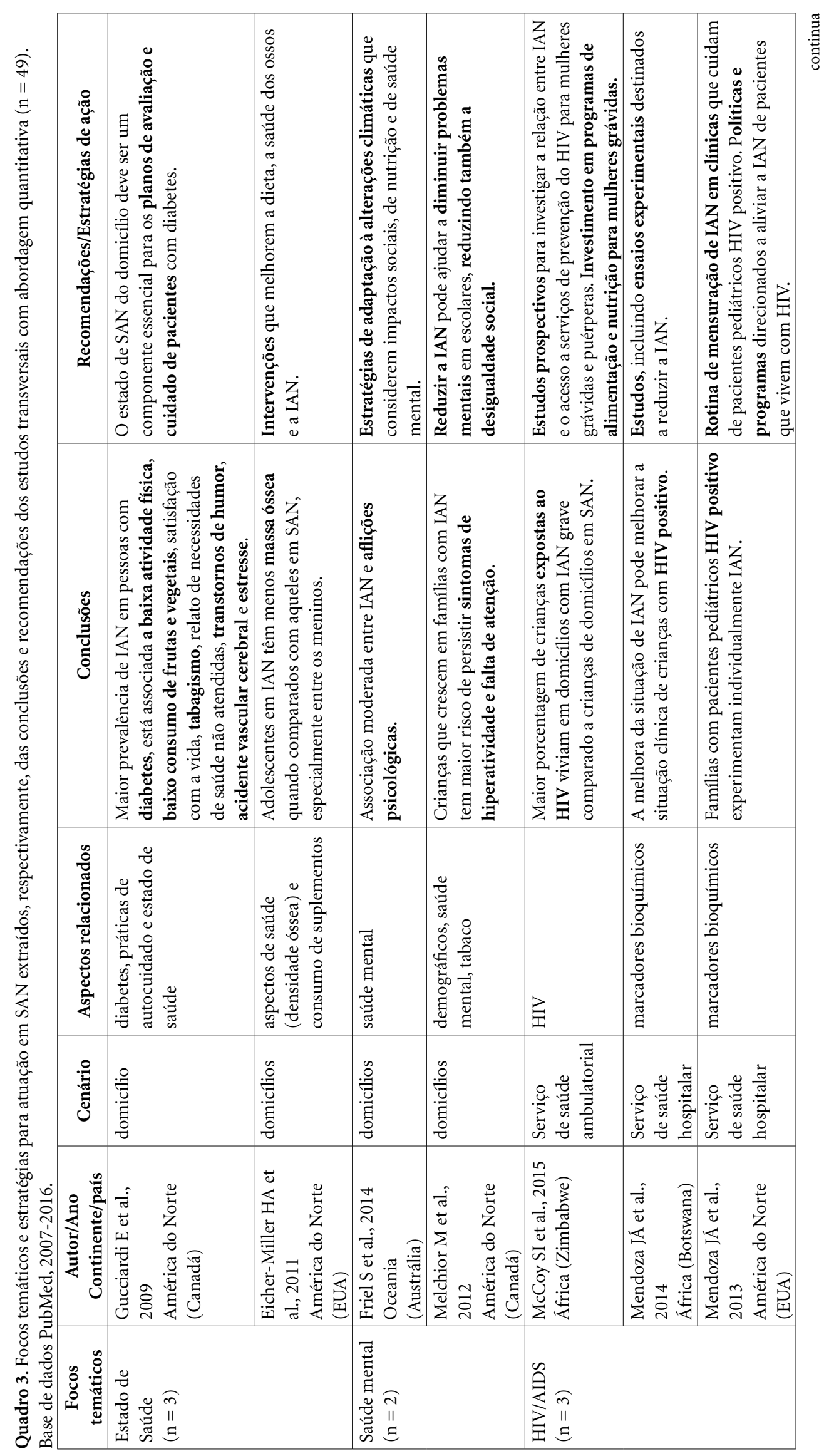




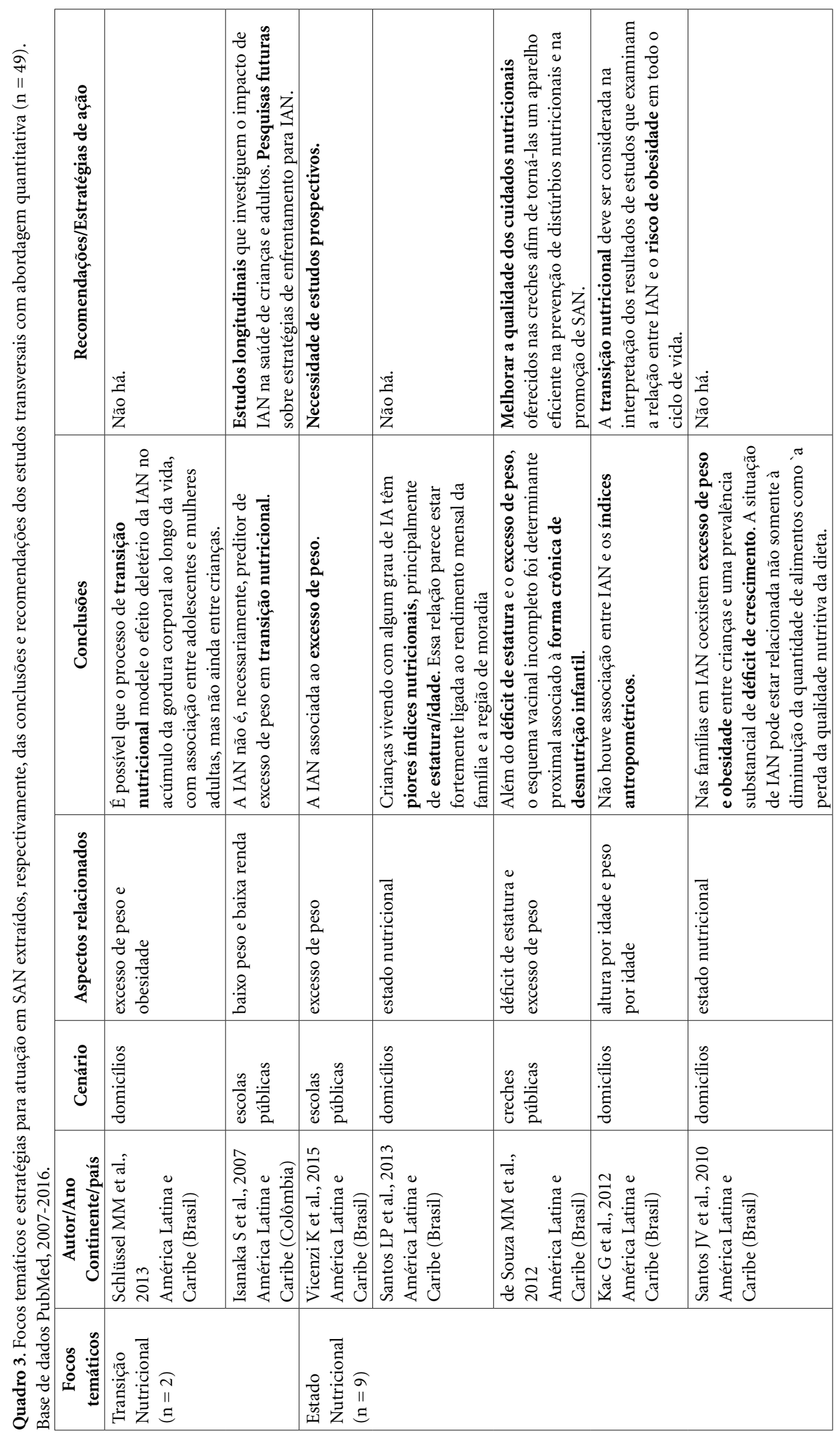




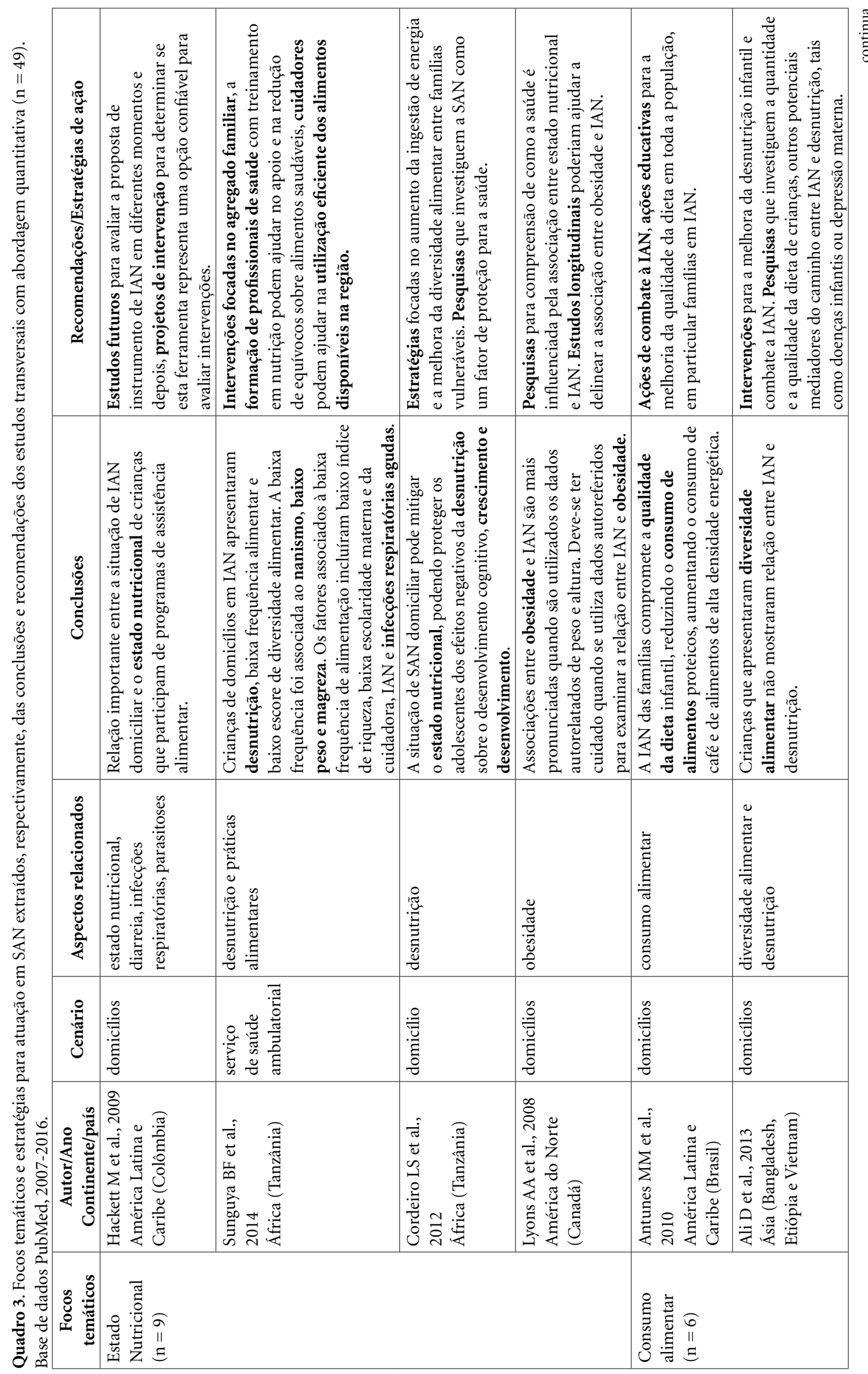




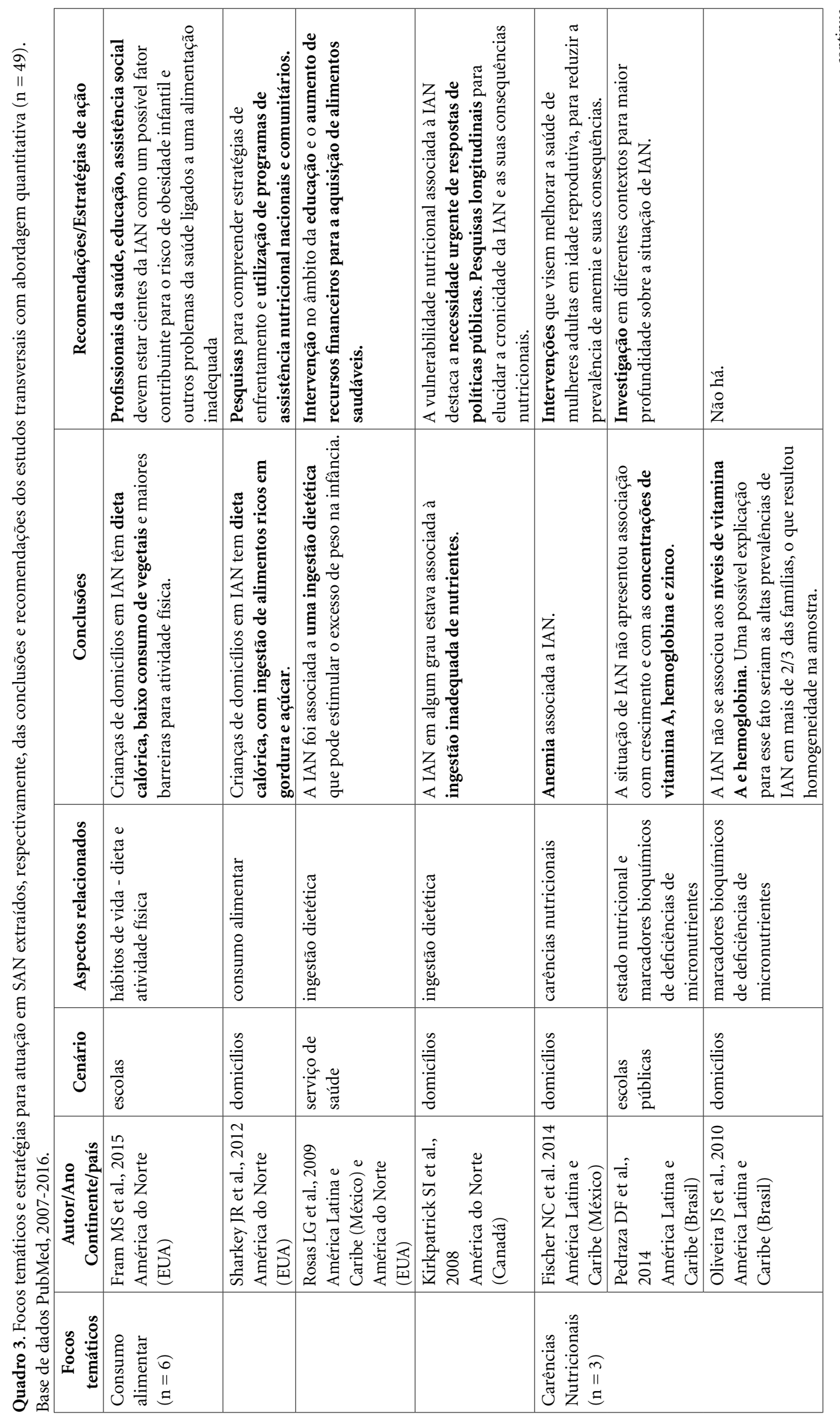




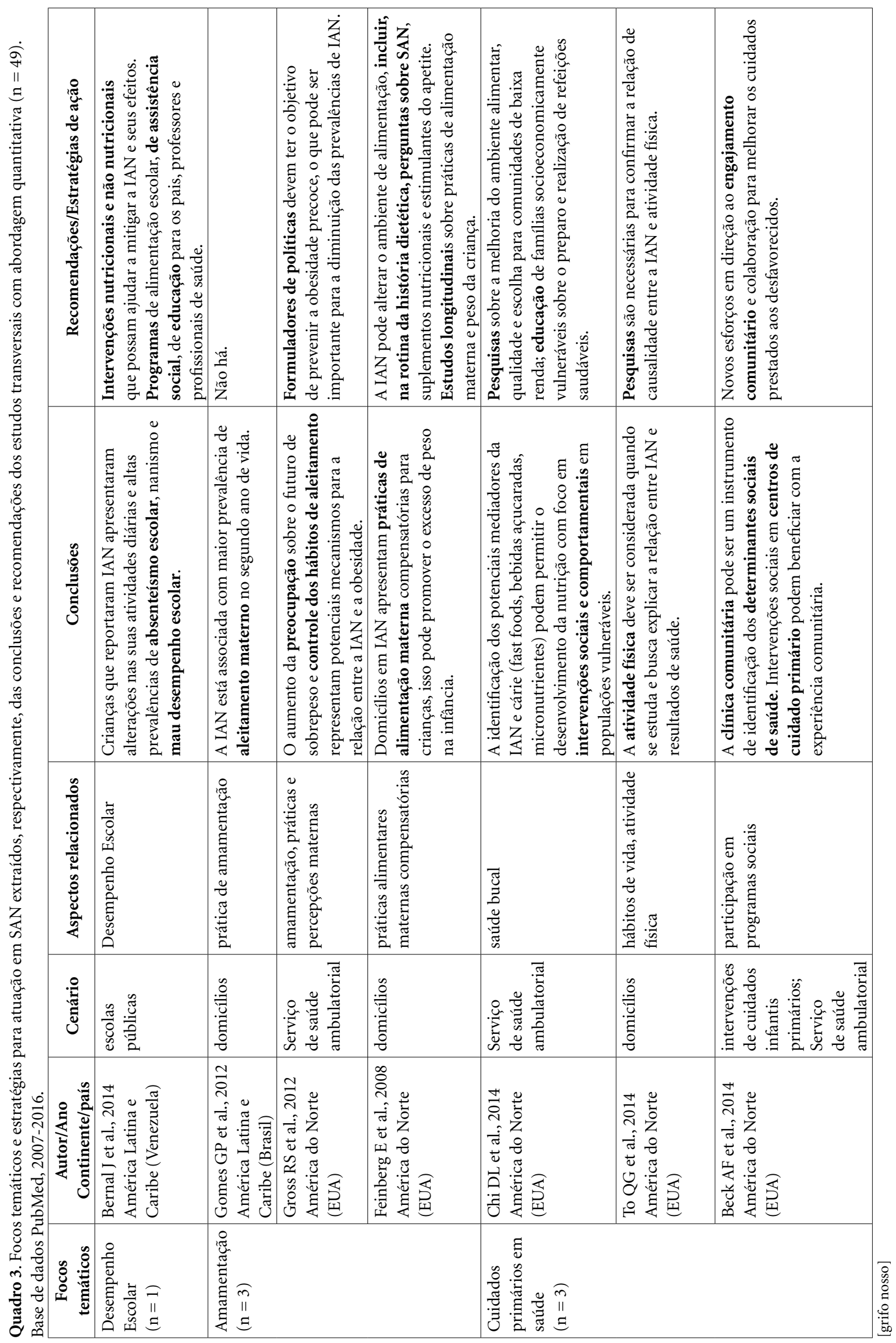


As conclusões/considerações finais dos estudos possibilitaram identificar 17 focos temáticos para a compreensão da situação de IAN nos diferentes continentes. Foram comuns nos estudos de abordagem qualitativa (Quadro 1) e quantitativa (Quadros 2 e 3) os seguintes focos temáticos: sistemas alimentares, pobreza e condições de renda, ambiente social e ambiente alimentar e consumo alimentar.

Os estudos com abordagem quantitativa longitudinal e transversal trouxeram maior diversidade de focos temáticos. Os estudos com abordagem quantitativa longitudinal contribuíram para a compreensão da situação de IAN em contextos de desastres naturais, destacaram questões de gênero, o desenvolvimento e crescimento infantil (Quadro 2).

Os estudos com abordagem quantitativa transversal trouxeram a situação de IAN entre pessoas como HIV/Aids, em contextos de transição nutricional e sinalizam a importância dos cuidados primários em saúde para a SAN (Quadro 3). Estes estudos apresentaram em comum, informações importantes sobre os grupos mais vulneráveis à IAN (escolares do gênero feminino, refugiados e imigrantes, órfãos e mulheres), questões ligadas ao estado de saúde, a saúde mental, ao estado nutricional, as carências nutricionais, ao consumo alimentar, a amamentação e ao desempenho escolar de crianças e adolescentes (Quadros 2 e 3).

Nas recomendações dos estudos foi possível identificar as estratégias de ação para atuação em SAN, expressas por meio das sugestões de políticas, programas e ações em diferentes cenários (escolas, domicílios e serviços de saúde), com diferentes atores (gestores, profissionais de saúde, professores, cuidadores, pais, movimentos sociais e associações comunitárias), e a necessidade do envolvimento de outros setores como educação e agricultura. Além disso, os estudos recomendaram a realização de mais pesquisas longitudinais, ensaios experimentais e intervenções (Quadros 1, 2 e 3$)$.

\section{Discussão}

A compreensão da alimentação na perspectiva da SAN possibilita partir de um marco conceitual mais abrangente, considerar alguns aspectos do processo saúde-doença nos âmbitos coletivo e individual, como, por exemplo, o sistema político -econômico mundial, o reconhecimento da SAN como um direito humano, os serviços de saúde e de educação, o comportamento e os hábitos alimentares $^{22}$. Em complemento a essa noção também é possível abarcar dimensões analíticas um pouco mais específicas que corroboram para o entendimento da alimentação na perspectiva da SAN, tomando como foco: o direito humano (realização de direitos e justiça social), os aspectos biológicos (aspectos nutricionais, sanitário e sensorial), sociocultural (sistema de valores, relação entre indivíduos e coletivos com a comida), econômico (relações de trabalho estabelecidas no âmbito do sistema alimentar, preço dos alimentos) e ambiental (formas de produção, comercialização e consumo de alimentos) ${ }^{23}$.

A literatura da área da saúde de modo geral apresenta estudos que abordam algumas dessas dimensões analíticas ${ }^{24-26}$. No entanto, o foco principal é o aspecto biológico, com predomínio da abordagem quantitativa epidemiológica, sendo necessários estudos qualitativos que possam contribuir para reflexões e proposições ampliadas para o campo da saúde pública, com abordagens que possibilitam a compreensão da alimentação como um direito humano e sua relação com outros direitos fundamentais, como saúde, moradia, educação, trabalho, participação e informação.

Os artigos analisados nesta revisão possibilitaram conhecer os diferentes continentes nos quais foram realizadas pesquisas empíricas sobre a situação de IAN, a diversidade dos cenários urbanos investigados e os aspectos relacionados a essa questão. Apesar dos estudos não tratarem diretamente do DHAA como objeto de investigação ou mesmo tê-lo como caminho principal de discussão, eles elucidaram questões relacionadas à situação de IAN, que permitiram identificar focos de compreensão e estratégias de ação para a atuação em SAN, que visam a garantia e a efetivação do DHAA. Além disso, sinalizaram a conexão entre a SAN e a saúde pública, principalmente, pela diversidade temática extraída dos estudos (Figura 2). No entanto, é uma conexão que ainda necessita ser fortalecida.

Os focos temáticos centraram-se nos aspectos da disponibilidade, do acesso e da produção dos alimentos, além da sua utilização biológica com foco nas doenças associadas à nutrição. Porém, para a compreensão da alimentação como um direito humano é necessário fortalecer focos temáticos como: sistemas alimentares, pobreza e condições de renda, ambiente social e ambiente alimentar, grupos mais vulneráveis à IAN, gênero, estado de saúde, saúde mental, amamentação, desempenho escolar, cuidados primários em saúde, cultura alimentar, produção regional e local 
dos alimentos. Visando fortalecer a importante relação do DHAA com os outros direitos sociais, fundamentais: a saúde, a educação, a moradia, o trabalho e o lazer.

Os direitos humanos são um conjunto de direitos universais, indivisíveis, inalienáveis, interdependentes e inter-relacionados que todo ser humano possui ao nascer ${ }^{27}$. Assim, quando existe a violação de um direito, muito provavelmente há a violação concomitante de outros ${ }^{28}$. Os direitos humanos são metas desejáveis e fins que devem ser perseguidos. No entanto, entre os problemas que os envolvem, destacam-se a necessidade de protegê-los mais do que justifica-los enquanto norma jurídica e o seu enfrentamento como um problema político ${ }^{29}$.

A alimentação é um direito que está relacionado a outros direitos humanos, como a saúde (nutrição), a vida (fome, desnutrição), a água (preparo, higiene e consumo), a moradia (espaço para cozinhar; e que no caso de aluguel, pode concorrer com a falta de renda para a aquisição de alimentos), a educação (conhecimento sobre alimentação), o trabalho e a seguridade social (obter alimentos ou ter benefícios de transferência de renda), a participação (cidadania e engajamento político, participação nas ações governamentais), a informação (escolha para consumo), o trabalho infantil (estratégia utilizada para comprar alimentos em situação de escassez) e a privação de liberdade (prisão) ${ }^{4}$.

No ano de 2004 a ONU lançou as Diretrizes Voluntárias em apoio à realização progressiva do direito à alimentação adequada no contexto da segurança alimentar nacional, que representaram a primeira iniciativa de governos em interpretar um direito econômico, social e cultural e apoiar a sua efetivação enquanto um direito humano fundamental. A partir disso, inicia-se o incentivo ao reconhecimento e a criação de garantias (jurídicas, programáticas, orçamentárias e democráticas) para a efetivação do DHAA no âmbito nacional dos países ${ }^{21}$. O que requer um caminho considerável de disputas, lutas e conquistas políticas entre Estado e sociedade. No âmbito da produção científica, o incentivo de investigação do tema da SAN a partir desse período pode ter ocorrido, visto que os anos de maiores publicações ocorreram a partir de 2009. Pode-se perscrutar que isso tenha ocorrido para a realização de pesquisas que trouxessem o diagnóstico da situação de IAN nos países.

Ao discutir os estudos analisados, é importante considerar as diferenças políticas, econômicas, sociais e culturais existentes em cada país, por conta da influência que isso tem nas concepções locais do que é IAN e na criação das garantias para a efetivação do DHAA. Contudo, alguns princípios são fundantes para a garantia e a efetivação desse direito, como a participação social, a prestação de contas e a transparência, a não-discriminação em favor da inclusão, o respeito à dignidade humana, a delegação de poder/ responsabilidade e a existência efetiva de um Estado de direito ${ }^{30}$. A partir dos estudos analisados observou-se que tanto nos países desenvolvidos quanto nos países em desenvolvimento a alimentação ainda carece ser efetivada como um direito humano que visa à dignidade e a justiça social para todas as pessoas.

Nos cenários urbanos, os imigrantes, refugiados, mulheres e crianças são grupos de pessoas mais vulneráveis à IAN e os direitos humanos fundamentais como à saúde, a educação, o trabalho e a moradia quando não garantidos atingem diretamente o DHAA. Neste sentido, não há como ignorar que as interações e práticas locais refletem os contextos mais globais, revelando as relações de poder nas questões que dizem respeito à vida ou que ameaçam o tecido social ${ }^{31,32}$. Assim, a situação de IAN descortina, por exemplo, a desigualdade de gênero quando o tema é a alimentação.

Nos países em desenvolvimento, a situação socioeconômica da população é um aspecto importante que deve ser considerado na concretização do DHAA, pois ainda que haja expansão, crescimento e desenvolvimento da economia e certa melhora nos indicadores sociais, as desigualdades sociais e econômicas, étnico-raciais, de gênero e de acesso e disponibilidade aos alimentos permanecem como problemas estruturais a serem enfrentados ${ }^{2,33,34}$.

A pobreza continua sendo uma das principais causas para mortalidade prematura no cenário contemporâneo e tem contribuído para doenças e agravos que se expressam no comprometimento das condições de saúde ${ }^{35}$ e alimentação da população ${ }^{36}$. $\mathrm{O}$ ato de se alimentar se desenvolve e envolve regras sociais, ambiente, trajetória individual e valores de grupos (pertencimento). Na sociedade contemporânea, vive-se um paradoxo da oferta abundante de alimentos ricos em açúcar, sal e gordura e da intensa publicidade de opções alimentares convenientes, por um lado; e das mensagens da nutrição por uma alimentação saudável e a busca constante por um corpo fitness, por outro lado, que geram conflitos nas escolhas e no consumo alimentar ${ }^{9,37}$.

A disponibilidade, o acesso, o consumo e a utilização biológica dos alimentos são alguns dos 
elementos que compõem a situação de SAN. Tanto no nível domiciliar, quanto individual, a IAN se revela como um processo progressivo, gerenciado por meio de táticas presentes nos âmbitos domiciliar e individual ${ }^{22}$. Deste modo, conhecer a situação de IAN da população (diagnóstico), monitorar e avaliar as políticas públicas e ações existentes (monitoramento e avaliação), formar atores para atuar como conhecedores do DHAA (formação de atores) e implementar ações de advocacia para o acompanhamento dos orçamentos públicos investidos na realização deste direito (advocacia) parecem ser estratégias cruciais para a efetivação do DHAA no âmbito local ${ }^{3,34}$. Além de ações conjuntas intersetoriais entre o setor saúde e setores como saneamento, agricultura e abastecimento, educação, habitação e comunicação, que visem à promoção da saúde ${ }^{38}$.

Os estudos mostraram que os atores envolvidos no processo progressivo de realização do DHAA vão desde os titulares de obrigações (Estado e seus agentes), os titulares de responsabilidades (associações da sociedade civil organizada e movimentos sociais) até os titulares de direitos (todo ser humano, cidadão). Diante disso, a participação social nos processos de decisão e nas ações dos governos são de suma importância para a proteção dos direitos humanos e para o cumprimento das garantias orçamentárias dos Estados na implementação das políticas públicas que visam à efetivação desses direitos ${ }^{39}$.

No cenário contemporâneo, os direitos humanos estão ameaçados, principalmente, no caso de crianças e adolescentes que dependem de pais, familiares, cuidadores ou responsáveis para manterem sua existência. Tal cenário compromete o crescimento e o desenvolvimento deste grupo para alcançarem a sua vida adulta ${ }^{40}$, colocando em disputa a existência de gerações futuras.

\section{Considerações finais}

Esta revisão integrativa da literatura possibilitou conhecer a multidimensionalidade dos aspectos relacionados à alimentação na perspectiva da SAN, a partir de focos temáticos para a compreensão da alimentação como um direito humano e das diferentes estratégias de ação. Dentre os focos temáticos se destacam: sistemas alimentares, pobreza e condições de renda, ambiente social e ambiente alimentar, consumo alimentar, HIV/ AIDS, saúde mental, estado nutricional, carências nutricionais, amamentação e desempenho escolar. Das estratégias de ação para a efetivação do DHAA foram recomendadas: políticas, programas e ações em diferentes cenários (domicílios, serviços de saúde e escolas), com diferentes atores (gestores, profissionais de saúde, professores, cuidadores, pais, movimentos sociais e associações comunitárias) e a necessidade do envolvimento de outros setores como educação e agricultura, ou seja, ações intersetoriais.

Em síntese os estudos analisados mostram a importância dos cuidados primários em saúde para a efetivação do DHAA no setor saúde, destacam questões de gênero e apontam os grupos mais vulneráveis à IAN. Elucidam a complexidade do problema abordado e reforçaram o pressuposto de que existem poucos estudos que investigam e discutem a alimentação como um direito humano, além de poucos estudos com abordagem qualitativa.

A efetivação do DHAA tanto nos países desenvolvidos quanto nos países em desenvolvimento está em disputa enquanto via de concretização de justiça social e garantia das gerações futuras. Diante disso, a produção científica da área da saúde que se dedicou à análise empírica da SAN em diferentes cenários urbanos com crianças e adolescentes parece se orientar por um caminho que direciona e dá mais ênfase aos aspectos biológicos. O que tende a localizar as discussões numa argumentação pouco fecunda para a compreensão e disputa da alimentação como um direito humano.

Embora este estudo tenha investido esforços na análise e compreensão dos artigos que abordam contextos urbanos e não tenha incluído artigos com investigação em cenários rurais, comunidades tradicionais de pescadores, quilombolas e indígenas e com populações adultas, reconhece-se a importância dessa investigação para a SAN e o DHAA. A análise desses artigos possibilitaria maior discussão dos aspectos ligados à reforma agrária, a regulação fundiária e o reconhecimento dos territórios para maior autonomia dos povos.

Adicionalmente, reconhece-se que a produção científica analisada colaborou para o diagnóstico da SAN nos diferentes países, inclusive no Brasil. No entanto, há um importante caminho a ser percorrido para a compreensão da alimentação como um direito e há insuficiência de estudos que investigam e discutam o DHAA.

Sugere-se que futuras pesquisas e publicações da área da saúde, particularmente, do campo da saúde pública (que supostamente teria um compromisso com a agenda dos direitos humanos fundamentais), avancem na ampliação da noção 
da alimentação como um direito humano, buscando promover mudanças nos rumos do debate da SAN com enfoques e estratégias voltadas para o enfrentamento das questões políticas, econômicas e sociais inerentes a essa temática.

\section{Colaboradores}

LDS Guerra trabalhou na concepção, redação e revisão do manuscrito; AM Cervato-Mancuso colaborou na orientação e revisão do manuscrito; ACD Bezerra colaborou na revisão do manuscrito.

\section{Agradecimentos}

Ao Programa de Pós-Graduação em Nutrição em Saúde Pública da Faculdade de Saúde Pública da Universidade de São Paulo, no qual foi defendida a tese de doutorado que originou este artigo (intitulada "Direito Humano à Alimentação e atuação profissional em saúde pública”, ano de 2017). À Christiane Gasparini Araujo Costa (Presidente do Conselho de Segurança Alimentar e Nutricional do Município de São Paulo - Comusan, Coordenadora de Segurança Alimentar e Nutricional do Instituto Pólis, Membro da coordenação do Fórum Brasileiro de Soberania e Segurança Alimentar e Nutricional - FBSSAN) e Cristiane da Silva Cabral (Professora do Departamento de Ciclos de vida, Saúde e Sociedade da Faculdade de Saúde Pública da Universidade de São Paulo) pela revisão crítica do manuscrito e por participarem como membros da banca examinadora da defesa de doutorado. 


\section{Referências}

1. Ribeiro H, Jaime PC, Ventura D. Alimentação e sustentabilidade. Estudos Avançados 2017; 31(89):185198.

2. Haddad L, Hawkes C, Webb P, Thomas S, Beddington J, Waage J, Flynn D. A new global research agenda for food. Nature 2016; 540(7631):30-32.

3. Food and Agriculture Organization of the United Nations (FAO-UN). Cadernos de trabalho sobre o direito à alimentação. Roma: FAO-UN; 2014.

4. Food and Agriculture Organization of the United Nations (FAO-UN). The Rigth to Adequate Food. Human Rigths. Fact Sheet No 34. Office of the United Nations High Commissioner for Human Rights. New York: FAO -UN; 2010.

5. Magalhães R. Regulação de alimentos no Brasil. $R$ Dir Sanit 2017; 17(3):113-133.

6. Machado PP, Oliveira NRF, Mendes AN. O indigesto sistema do alimento mercadoria. Saúde Soc 2016; 25(2):505-515.

7. Konzernatlas Atlas das Multinacionais 2017. Ideias na Mesa [documento da internet]. 2017. [acessado 2017 Jan 26]. Disponível em: http://www.ideiasnamesa. unb.br/index.php? $r=$ noticia/view\&id $=2283$

8. International Food Policy Research Institute (IFPRI). Global Nutrition Report 2016: From Promise to Impact: Ending Malnutrition by 2030. Washington: IFPRI; 2016.

9. Monteiro CA, Cannon G. The impact of transnational "Big Food" Companies on the South: a view from Brazil. PLOSmedicine 2012; 9(7):1-5.

10. Lobstein T, Jackson-Leach R, Moodie ML, Hall KD, Gortmaker SL, Swinburn BA, James WP, Wang Y, McPherson K. Child and adolescent obesity: part of a bigger picture. Lancet 2015; 385(20):2510-2520.

11. World Health Organization (WHO). Global Status Report on noncommunicable diseases 2014: "Attaining the nine global noncommunicable diseases targets; a shared responsibility". Geneva: WHO; 2014.

12. World Health Organization (WHO). UN-Habitat. Global Report on Urban Health: equitable, healthier cities for sustainable development. Geneva: WHO; 2016.

13. United Nations Children's Fund (UNICEF). The state of the world's children 2012: children in an urban world. New York: UNICEF; 2012.

14. Food and Agriculture Organization of the United Nations (FAO-UN). El estado de la inseguridade alimentaria en el mundo. Cumplimiento de los objetivos internacionales para 2015 em relación el hambre: balance de los desiguales progresos. Roma: FAO-ONU; 2015.

15. Organización de las Naciones Unidas para la Alimentación y la Agricultura (FAO-ONU). Organización Panamericana de la Salud (OPAS). América Latina y el Caribe - Panorama de la Seguridad Alimentaria y Nutricional: Sistemas alimentarios sostennibles para poner fin al hambre y la malnutrición. Santiago: FAO-ONU, OPAS; 2016.

16. Santin GC, Pintarelli TP, Fraiz FC, Oliveira ACB, Paiva SM, Ferreira FM. Association between untreated dental caries and household food insecurity in schoolchildren. Cien Saude Colet 2016; 21(2):573-584.
17. Young S, Wheeler AC, McCoy SI, Weiser SD. A review of the role of food insecurity in adherence to care and treatment among adult and pediatric populations living with HIV and AIDS. AIDS Behav 2014; 18(Supl. 5):S505-515.

18. Mendes KDS, Silveira RCCP, Galvão CM. Revisão integrativa: método de pesquisa para a incorporação de evidências na saúde e na enfermagem. Texto Contexto Enferm 2008; 17(4):758-764.

19. Bauer MW, Gaskell G. Pesquisa qualitativa com texto, imagem e som: um manual prático. Rio de Janeiro: Vozes; 2002. p. 393-415.

20. Organização das Nações Unidas (ONU). Comitê de Direitos Econômicos, Sociais e Culturais do Alto Comissariado de Direitos Humanos. Comentário Geral número 12: O direito humano à alimentação. New York: ONU; 1999.

21. Food and Agriculture Organization of the United Nations (FAO-UN). O direito à alimentação. Diretrizes voluntárias em apoio à realização progressiva do direito à alimentação adequada no contexto da segurança alimentar e nutricional. Roma: FAO-UN; 2015.

22. Kepple AW, Segall-Corrêa AM. Conceituando e medindo segurança alimentar e nutricional. Cien Saude Colet 2011; 16(1):187-199.

23. Castro I. Desafios e perspectivas para a promoção da alimentação adequada e saudável no Brasil. Cad Saude Publica 2015; 31(1):7-9.

24. Bezerra TA, Olinda RA, Pedraza DF. Insegurança alimentar no Brasil segundo diferentes cenários sociodemográficos. Cien Saude Colet 2017; 22(2):637-651.

25. Sichieri R, Pereira R. A. Revista de Saúde Pública: 50 years disseminating the knowledge in nutrition. Rev Saude Publica 2016; 50(72):1-12.

26. Pomeranz JL, Miller DP. Policies to promote healthy portion sizes for children. Appetite 2015; 88:50-58.

27. Organização das Nações Unidas (ONU). Declaração Universal dos Direitos Humanos, 1948. [documento da internet]. 1948 [acesso 2016 Nov 5]. Disponível em: http://www.un.org/en/documents/udhr/index.shtml

28. Gruskin S, Mills EJ, Tarantola D. Health and Human Rights 1 History, principles, and practice of health and human rights. Lancet 2007; 370(9585):449-455.

29. Bobbio N. Sobre os fundamentos dos direitos do homem. In: Bobbio N. A era dos direitos. Rio de Janeiro: Campus; 1992. p. 15-24.

30. Food and Agriculture Organization of the United Nations (FAO-UN). O Direito Humano à Alimentação Adequada no marco estratégico global para a segurança alimentar e nutricional. Consenso global. Roma: FAO -UN; 2014.

31. Langdon EJ. Os diálogos da antropologia com a saúde: contribuições para as políticas públicas. Cien Saude Colet 2014; 19(4):1019-1029.

32. Costa CGA. Alimentação como um direito humano. In: Costa CGA, organizador: Segurança alimentar e nutricional: significados e apropriações. São Paulo: Annablume, Fapesp; 2011. p. 162-182. 
33. Nunnery DL, Dharod JM. Potential determinants of food security among refugees in the U.S.: an examination of pre- and post- resettlement factors. Food Sec 2017; 9(1):163-179.

34. Rocha C, Burlandy L, Magalhães R. Segurança Alimentar e Nutricional: perspectivas, aprendizados e desafios para as políticas públicas. Rio de Janeiro: Fiocruz; 2013.

35. Stringhini S, Carmeli C, Jokela M, Avendaño $M$, Muennig P, Guida F, Ricceri F, d'Errico A, Barros H, Bochud M, Chadeau-Hyam M, Clavel-Chapelon F, Costa G, Delpierre C, Fraga S, Goldberg M, Giles GG, Krogh V, Kelly-Irving M, Layte R, Lasserre AM, Marmot MG, Preisig M, Shipley MJ, Vollenweider P, Zins M, Kawachi I, Steptoe A, Mackenbach JP, Vineis P, Kivimäki M. Socioeconomic status and the $25 \times 25$ risk factors as determinants of premature mortality: a multicohort study and meta-analysis of 1.7 million men and women. Lancet 2017; 389(10075):1229-1237.

36. Organization of the United Nations. The Internacional Policy Centre for Inclusive Growth. United Nations Development Programme. Policy in Focus. Food and nutrition security towards the full realization of human rights. Brasília: ONUDP; 2016.

37. Alvarenga M, Figueiredo M, Timerman F, Antonaccio C. Nutrição comportamental. Barueri: Manole; 2015.

38. Burlandy L, Rocha C, Maluf MMM, Ferreira DM, Pereira SEAC. International cooperation for food and nutrition security: Systematization of the participatory, contextualized, and intersectoral educational practices. Rev Nutr 2016; 29(6):929-946.

39. Pinto EG. Novo regime fiscal e a constitucionalização do contingenciamento das despesas primárias obrigatórias. Physis 2016; 26(4):1097-1101.

40. Nord M, Hopwood H. Recent advances provide improved tools for measuring children's food security. $J$ Nutr 2007; 137(3):533-536.

Artigo apresentado em 23/05/2017

Aprovado em 07/02/2018

Versão final apresentada em 09/02/2018 